\title{
DISTRIBUTION-FREE EXPONENTIALLY WEIGHTED MOVING AVERAGE CONTROL CHARTS FOR MONITORING UNKNOWN LOCATION
}

\author{
M.A. Graham \\ Department of Statistics \\ University of Pretoria \\ South Africa
}

marien.graham@up.ac.za

\author{
A. Mukherjee \\ Department of Mathematics \\ Indian Institute of Technology \\ Madras \\ India \\ amitmukh2@yahoo.co.in
}

\author{
S. Chakraborti \\ Department of Information \\ Systems, Statistics and \\ Management Science \\ University of Alabama \\ schakrab@cba.ua.edu
}

\begin{abstract}
Distribution-free (nonparametric) control charts provide a robust alternative to a data analyst when there is lack of knowledge about the underlying distribution. A two-sided nonparametric Phase II exponentially weighted moving average (EWMA) control chart, based on the exceedance statistics (EWMA-EX), is proposed for detecting a shift in the location parameter of a continuous distribution. The nonparametric EWMA chart combines the advantages of a nonparametric control chart (known and robust in-control performance) with the better shift detection properties of an EWMA chart. Guidance and recommendations are provided for practical implementation of the chart along with illustrative examples. A performance comparison is made with the traditional (normal theory) EWMA chart for subgroup averages and a recently proposed nonparametric EWMA chart based on the Wilcoxon-MannWhitney statistics. A summary and some concluding remarks are given.
\end{abstract}

Keywords: Binomial, Nonparametric, Markov chain, Quality control, Robust, Run-length, Search algorithm, Simulation

\section{Introduction}

The exponentially weighted moving average (EWMA) control charts have enjoyed widespread popularity in practice with data analysts. These charts are similar to the cumulative sum (CUSUM) charts in the sense that they both use accumulated data up until the most recent time point in order to detect process shifts. These sequential charts are particularly effective in detecting relatively small and persistent changes (step shifts) in the process (see e.g. Montgomery, 2009 pages 400 and 419). However, the EWMA charts are preferred by some in the industry. They are easier to implement and as Steiner and Jones (2010) put it, "The main advantage of an EWMA is that it provides an ongoing local estimate of the average score...Another minor advantage is the inherent two-sided nature of an EWMA." Traditional EWMA charts for subgroup averages were introduced by Roberts (1959) and since then there has been a tremendous amount of work on EWMA charts (see e.g. the overview by Ruggeri et al. (2007) and the references therein). Some newer references include Huwang et al. (2010), Maravelakis and Castagliola (2009) and $\mathrm{Su}$ et al. (2011). In typical applications of the 
traditional EWMA charts for subgroup averages it is usually assumed that the underlying process distribution is normal, or, at least, approximately so. However, in certain situations in practice, the normality assumption may not be tenable or justifiable for lack of information or data. Human et al. (2011) recently showed that the traditional EWMA chart can lack in-control (IC) robustness for some non-normal distributions such as the symmetric bi-modal and the contaminated normal distribution. Their observations call into question routine applications of the traditional EWMA chart in practice. It should be noted that although Montgomery (2001) page 433 stated "It (the EWMA) is almost a perfectly nonparametric (distribution-free) procedure" based on a similar conclusion by Borror et al. (1999), these statements were made for the case where the process parameters (i.e. process mean and standard deviation) are known or specified and it was seen to be true only for certain values of the smoothing parameter. As noted earlier, Human et al. (2011) showed the parametric EWMA typically used for the known parameter case can be non-robust to the normality assumption. In fact, when the process parameters are unknown and need to be estimated using a reference sample the traditional EWMA chart was shown to be non-robust for a large number of non-normal distributions. Thus development and application of distribution-free (or nonparametric) EWMA charts seem desirable as they do not depend on a particular distributional assumption and their IC performance is the same for all continuous distributions. For a thorough account of the nonparametric control charts literature see Chakraborti et al. (2001), Chakraborti and Graham (2007) and Chakraborti et al. (2011). Graham et al. (2011a,b) recently considered nonparametric EWMA charts based on the sign and the signed-rank test statistics, respectively, for the situation when the IC process median is specified or known. In many practical situations, the process median may not be known and would have to be estimated using a Phase I reference sample. It is well-known that ignoring the effects of estimation of parameters can be costly as the run-length properties of the chart are greatly impacted which can lead to, for example, many more false alarms than nominally expected. In this paper we consider a nonparametric EWMA chart for monitoring the unknown median using a reference sample. The proposed chart is an analogue of the EWMA sign chart considered in Graham et al. (2011a) and is based on what are known as precedence or exceedance test statistics.

The precedence test is a nonparametric test based on the number of observations from one of the samples that precede a specified (say the $r^{\text {th }}$ ) order statistic of the other sample. The precedence statistic is linearly related to the exceedance statistic, which is the number of observations from one of the samples that exceed the $r^{\text {th }}$ order statistic of the other sample, so that precedence and exceedance tests are equivalent. Precedence/exceedance tests have been 
found to be useful in a number of applications including quality control and reliability studies with lifetime data. The reader is referred to Balakrishnan and $\mathrm{Ng}$ (2006) for the vast literature on precedence/exceedance tests. In particular, they note that (page 51) "Wilcoxon's rank-sum test performs better than the precedence tests if the underlying distributions are close to symmetry, such as the normal distribution, gamma distribution with large values of shape parameter, and lognormal distribution with small values of shape parameter. However, under some right-skewed distributions such as the exponential distribution, gamma distribution with shape parameter 2.0, and lognormal distribution with shape parameter 0.5 , the precedence tests have higher power values than the Wilcoxon's rank-sum test for small values of $r$. It is evident that the more right-skewed the underlying distribution is, the more powerful the precedence test is." Motivated by these observations, Chakraborti et al. (2004) studied a class of nonparametric Phase II Shewhart-type charts based on the precedence statistics, called the Shewhart-type precedence charts. This paper has been the starting point for a number of follow-up papers in this area. Shewhart-type charts are popular in practice because of their simplicity and ease of application, they are good to detect larger transient-type shifts but it is known that they are less able to detect small and persistent process shifts quickly enough (see, for example, Montgomery (2009)). Mukherjee et al. (2012) proposed a Phase II nonparametric CUSUM chart based on the exceedance statistics, called the exceedance CUSUM chart, for detecting a right shift in the unknown location parameter of a continuous distribution. In this paper a two-sided nonparametric Phase II EWMA chart based on the exceedance statistics (denoted EWMA-EX) is considered for detecting a shift in the location parameter of a continuous distribution.

The rest of the article is organized as follows: In Section 2 the nonparametric EWMAEX chart is introduced. In Section 3 the run-length distribution is studied. In Section 4 we discuss two data analytic examples showing the application of the EWMA-EX chart in practice. The IC and out-of-control (OOC) chart performance of the EWMA-EX chart are studied and compared in Section 5 to some existing parametric and nonparametric control charts. We investigate the effect of the reference sample size in Section 6, after which we conclude with a summary in Section 7. Some mathematical results and computational algorithms are juxtaposed in the Appendix.

\section{Statistical background: EWMA-EX chart}

Assume that a Phase I reference sample $X_{1}, X_{2}, \ldots, X_{m}$ is available from an IC process with a cdf $F(x)$. Let $Y_{j 1}, Y_{j 2}, \ldots, Y_{j n}, j=1,2, \ldots$, denote the $j^{\text {th }}$ test Phase II sample of 
size $n$ from a cdf $G(y)$. Both $F$ and $G$ are unknown continuous distribution functions and the process is IC when $F=G$. For detecting a change in the location, we use the location model $G_{Y}(x)=F(x-\theta)$ where $\theta \epsilon[0, \infty)$ is the location parameter.

Let $U_{j, r}$ denote the number of exceedances, that is, the number of $Y$ observations in the $j^{\text {th }}$ Phase II sample that exceeds $X_{(r)}$, the $r^{\text {th }}$ ordered observation in the reference sample. The statistic $U_{j, r}$ is called an exceedance statistic and the probability $p_{r}=P\left[Y>X_{(r)} \mid X_{(r)}\right]$ is called an exceedance probability. The number of $Y$ observations in the $j^{\text {th }}$ Phase II sample that precede $X_{(r)}$ is called a precedence statistic and this statistic was used by Chakraborti et al. (2004) to study the Shewhart-type precedence charts. It can be shown that (see Result A.3 in Mukherjee et al. (2012)) the unconditional joint distribution of exceedance statistics is distribution-free and hence the proposed EWMA-EX chart is unconditionally distribution-free.

Constructing the EWMA-EX chart is straight forward. Note that since for a given value of the order statistic $X_{(r)}=x_{(r)}$, the variable $U_{j, r}$ follows a $\operatorname{binomial}\left(n, p_{r}\right)$ distribution, conditionally on $X_{(r)}$, we can construct a binomial-type EWMA chart using the $U_{j, r}$ 's to monitor the process location. Hence, the plotting statistic of the chart is given by

$$
Z_{j}=\lambda U_{j, r}+(1-\lambda) Z_{j-1} \text { for } j=1,2,3, \ldots
$$

where the starting value is taken as $Z_{0}=E\left(U_{j-k, r} \mid X_{(r)}\right)=n p_{r}$ and $0<\lambda \leq 1$ is the smoothing constant. Note that we get the Shewhart-type precedence chart of Chakraborti et al. (2004) when $\lambda=1$.

To calculate the control limits of the proposed chart the IC mean and standard deviation of $Z_{j}$ are necessary. It can be shown that the unconditional IC mean and standard deviation of $Z_{j}$ are given by

$$
\begin{gathered}
E\left(Z_{j}\right)=n(1-a)\left(1-(1-\lambda)^{j}\right) \\
\text { and } \\
\operatorname{STDEV}\left(Z_{j}\right)=\sqrt{\left(\frac{n a(1-a)}{m+2}\right)\left\{n\left(1-(1-\lambda)^{j}\right)^{2}+\frac{\lambda(m+1)}{2-\lambda}\left(1-(1-\lambda)^{2 j}\right)\right\}}
\end{gathered}
$$

respectively, where $a=r /(m+1)$ (see Appendix A for the derivation of these formulae). Hence, the proposed nonparametric EWMA-EX chart has a plotting statistic $Z_{j}$ given in (1) with $Z_{0}=n(1-a)$ and the exact time varying upper control limit $(U C L)$, lower control limit $(L C L)$ and centreline $(C L)$ of the chart are given by $C L=E\left(Z_{j}\right)$ and $U C L / L C L=E\left(Z_{j}\right) \pm L \times$ $\operatorname{STDEV}\left(Z_{j}\right)$ where the mean and the standard deviation are given in (2).

The corresponding unconditional "steady-state" control limits are given by 


$$
\begin{gathered}
C L=n(1-a) \\
\text { and } \\
U C L / L C L=n(1-a) \pm L \sqrt{\left(\frac{n a(1-a)}{m+2}\right)\left\{n+\frac{\lambda(m+1)}{2-\lambda}\right\}} .
\end{gathered}
$$

These limits are typically used when the EWMA-EX chart has been running for several time periods and are obtained from (2) as $j \rightarrow \infty$ so that $\left(1-(1-\lambda)^{j}\right)$ and $\left(1-(1-\lambda)^{2 j}\right)$ approach unity, respectively. If any $Z_{j}$ plots on or outside of either of the control limits, the process is declared OOC and a search for assignable causes is started. Otherwise, the process is considered IC and the charting procedure continues. The steady state control limits are used in this paper. Note that $\lambda$ and $L$ are the two design parameters of the chart which influence the chart's performance. Choice of $\lambda$ and $L$ is discussed in more detail in Section 3. Note also that the nonparametric EWMA chart looks and operates very much like the traditional EWMA chart for subgroup averages (denoted EWMA- $\bar{X}$ hereafter).

\section{Run-length distribution}

The performance of a control chart is studied via its run-length distribution. The mean $(A R L)$ and the standard deviation $(S D R L)$ of the run-length distribution are popular performance indicators but since the run-length distribution is right-skewed, many researchers now recommend examining a number of percentiles including the $5^{\text {th }}, 25^{\text {th }}$, median, $75^{\text {th }}$ and the $95^{\text {th }}$ percentiles to better characterize the run-length distribution. Lucas and Saccucci (1990) adapted the method as in Brook and Evans (1972) to compute the run-length distribution of an EWMA- $\bar{X}$ chart using the theory of a Markov chain. For a detailed discussion on how to implement the homogeneous Markov chain approach for a nonparametric EWMA control chart, see Graham et al. (2009, 2011a and 2011b) and, more specifically, for implementation of the Markov chain approach for the proposed chart the reader is referred to Appendix B. However, a practical disadvantage of the Markov chain approach is the slow speed, since a large number of states is needed to get accurate answers, and doing so requires inversion of a matrix of large dimension, which can be quite time consuming. Since some of the run-length characteristics (particularly the higher order percentiles) could not be computed accurately within a reasonable amount of time using the Markov chain approach, extensive computer simulation is used to estimate these quantities. The simulation algorithm is described in Appendix C.

\section{Choice of design parameters}

The choice of the chart design parameters $(\lambda, L)$ generally entails two steps: First, one finds the $(\lambda, L)$ combinations that yield the desired in-control $A R L$ (denoted $\left.A R L_{0}\right)$. This is 
done using a search algorithm to calculate the $A R L_{0}$ for a given $m, n, \lambda$ and $L$. This is followed by plotting $L$ against $A R L_{0}$ to find the exact $L$ for a given $m, n$, and $\lambda$. Second, one needs to choose, among these $(\lambda, L)$ combinations, the one that provides the best performance i.e. the smallest out-of-control $A R L$ (denoted $A R L_{\delta}$ ) for the shift $(\delta)$ that is to be detected. Note that, the smoothing parameter $0<\lambda \leq 1$ is typically selected first (which depends on the magnitude of the shift to be detected) and then the constant $L>0$ is selected (which determines the width of the control limits i.e. the larger the value of $L$, the wider the control limits and vice versa).

For implementation of the chart the first step is to choose $\lambda$. If small shifts (roughly 0.5 standard deviations or less) are of primary concern the typical recommendation is to choose a small $\lambda$, say equal to $0.01,0.025$ or 0.05 ; if moderate shifts (roughly between 0.5 and 1.5 standard deviations) are of greater concern choose $\lambda=0.10$, whereas if larger shifts (roughly 1.5 standard deviations or more) are of concern choose $\lambda=0.20$ (see e.g. Montgomery (2009), page 423). Next we choose $L$, in conjunction with the chosen $\lambda$, so that a desired nominal $A R L_{0}$ is attained.

Tables $1 \mathrm{a}$ and $1 \mathrm{~b}$ list some $(\lambda, L)$-combinations for the popular $A R L_{0}$ values of 370 and 500 for small to moderate reference sample sizes $m=49,99$ and 149 and subgroup sizes $n=5$ and 10, respectively. It should be noted that if $X_{(r)}$ is taken to be the median it is easier to be calculated when $m$ is odd. In each case, the run-length characteristics are calculated using simulation and are called the attained values. The first row of each cell in Tables $1 \mathrm{a}$ and $1 \mathrm{~b}$ shows the $A R L_{0}$ followed by the corresponding $S D R L_{0}$ in parentheses, whereas the second row shows the values of the IC $5^{\text {th }}, 25^{\text {th }}, 50^{\text {th }}, 75^{\text {th }}$ and $95^{\text {th }}$ percentiles (in this order).

$$
<\text { Insert Tables } 1 \mathrm{a} \text { and } 1 \mathrm{~b}>
$$

So, for example, in order to detect a small shift in the median with the nonparametric EWMA-EX chart with an $A R L_{0}$ of approximately 500 and $m=49$ and $n=5$, one can use the $(\lambda, L)$-combination: $(0.05,1.411)$. Tables $1 \mathrm{a}$ and $1 \mathrm{~b}$ should be useful for implementing the nonparametric EWMA-EX chart in practice.

\section{Examples}

\section{Example 1}

First we illustrate the proposed EWMA-EX chart using a well-known dataset from Montgomery (2001; Tables 5.1 and 5.2) on the inside diameters of piston rings manufactured by a forging process. The data given in Table 5.1 contain twenty-five retrospective or Phase I samples, each of size five, that were collected when the process was thought to be IC, i.e. $m=$ 125. These data are considered to be the Phase I reference data for which a goodness of fit test 
for normality is not rejected. The reference sample has a median equal to 74.001, i.e. $r=$ 63.and $X_{(63)}=74.001$. Table 5.2 of Montgomery (2001) contains fifteen prospective (Phase II) samples each of five observations $(n=5)$.

In their article on the overview of the nonparametric control charts literature Chakraborti et al. (2011) illustrated and compared two parametric and two nonparametric charts using these data sets. They considered the (i) parametric EWMA- $\bar{X}$ chart, (ii) parametric CUSUM- $\bar{X}$ chart, (iii) nonparametric EWMA chart based on the Wilcoxon rank-sum statistic (denoted EWMA-Rank) and (iv) nonparametric CUSUM chart based on the Wilcoxon ranksum statistic (denoted CUSUM-Rank). For more details on the EWMA-Rank and CUSUMRank charts the reader is referred to Li et al. (2010). The design parameters were taken so that $A R L_{0} \approx 500$ for each chart and it was found in Chakraborti et al. (2011) that the parametric EWMA- $\bar{X}$ and CUSUM- $\bar{X}$ charts signalled first at sample number 12 , whereas the EWMARank and CUSUM-Rank charts signalled later at sample number 13 (see Figures 3 and 4 of Chakraborti et al. (2011), respectively). For the proposed EWMA-EX chart we set $\lambda=0.10$ (similar to the $\lambda$ used in Chakraborti et al. (2011)) and $L=2.311$ so that $A R L_{0} \approx 500$. The EWMA-EX chart signals at sample number 14 (see Figure 1). This is not surprising, as normal theory methods usually outperform nonparametric methods when the normality assumption is satisfied. However, it should be noted that in practice normality can be in doubt or may not be justifiable for lack of information or data and a nonparametric method may be more desirable for the "just in case" scenario. The next example illustrates this type of a situation.

$$
<\text { Insert Figure1 }>
$$

\section{Example 2}

In practice the underlying process distribution is often unknown or other than the normal and this is where the nonparametric charts can be really useful. To illustrate the application of the EWMA-EX chart when the data follow a symmetric yet heavier tailed distribution (than the normal)we use some simulated data from the Laplace (or double exponential) distribution; $D E(0,1)$ which is known to have a median of zero and a standard deviation equal to $\sqrt{2}$. An IC reference sample of size $100(m=100)$ was generated from this distribution and each data point was scaled so that the transformed observations have a standard deviation of 1 . For the reference data we find the median equal to -0.023 . Next the Phase II samples, each of size $5(n=5)$, were independently and sequentially generated by transforming the observations from a $D E(0,1)$ distribution so that the resulting observations have a median of $\gamma / \sqrt{n}(=0.2236$ for $\gamma=0.5$ and $n=5)$ and a standard deviation of 1 . 
Consequently, the Phase II samples can be thought of as having been drawn from a process that is OOC in the median.

For the EWMA-EX, EWMA- $\bar{X}$ and EWMA-Rank charts we set $\lambda=0.05$ and, consequently, the corresponding control limits are found to be $(1.991,3.058),(-0.449,0.449)$ and $(234.2,295.8)$, respectively, so that $A R L_{0} \approx 500$ for each chart.From panels (a) and (c) in Figure 2 we see that both the EWMA-EX and EWMA-Rank charts signal at sample number 24, respectively. This is not surprising, as the performance of the EWMA-EX and EWMARank charts are very similar for the Laplace distribution (see Table 4). Although both charts signal at sample number 24, it should be noted that the EWMA-EX chart signals at both sample numbers 24 and 25, whereas the EWMA-Rank only signals at sample number 24. From panel (b) in Figure 2 we see that although the EWMA- $\bar{X}$ chart has a steep incline, it doesn't signal. This example shows that there are situations in practice where the EWMA-EX chart offers an effective alternative over available parametric and nonparametric control charts.

$<$ Insert Figures 2a, 2b and 2c $>$

\section{Performance comparison}

The IC performance of a chart shows how robust a chart is, with respect to the nominal $A R L_{0}$, whereas the OOC performance needs to be examined to assess the chart's efficacy, which is its effectiveness in detecting a shift. From a practical standpoint, it is also of interest to compare the OOC performance of the proposed EWMA-EX chart with existing competing charts; we compare it to the EWMA- $\bar{X}$ and the EWMA-Rank chart, respectively. For the EWMA $-\bar{X}$ chart the parameters are estimated from a Phase I reference sample, duly taking care of the issues related to estimation.

Our study includes a collection of non-normal distributions and considers heavy-tailed, symmetric and skewed distributions. Specifically, the distributions considered in the study are:(a) the standard normal distribution, $N(0,1)$, (b) the exponential distribution with mean 1 , which is $\operatorname{GAM}(1,1)$, (c) the Laplace (or double exponential distribution $D E(0,1)$ ) distribution with mean 0 and variance 2 which is standard normal like, but has heavier tails, (d) the Symmetric Mixture Normal distribution $\left[0.6 N\left(\mu_{1}=0, \sigma_{1}=0.25\right)+0.4 N\left(\mu_{2}=0, \sigma_{2}=4\right)\right]$, (e) two Asymmetric Mixture Normal distributions with parameters $\left[0.6 N\left(\mu_{1}=0.25, \sigma_{1}=\right.\right.$ $\left.0.25)+0.4 N\left(\mu_{2}=0, \sigma_{2}=4\right)\right]$ and $\left[0.6 N\left(\mu_{1}=-0.25, \sigma_{1}=0.25\right)+0.4 N\left(\mu_{2}=0, \sigma_{2}=4\right)\right]$, respectively, and (f) the Log-Logistic $(\alpha=1, \beta=2.5)$ distribution. The Log-Logistic distribution (see for example, Meeker and Escobar, 1998, page 89) arises as the distribution of a positive valued random variable whose logarithm follows the familiar logistic distribution. 
Its shape is similar to that of a log-normal distribution but with heavier tails. This distribution is used to consider a heavy-tailed right-skewed distribution in our simulations. In the quality literature, Kantam and Rao (2005) considered CUSUM charts for Log-Logistic data.

Because the EWMA-EX chart is nonparametric, the IC run-length distribution and the associated characteristics remain the same for all continuous distributions. In other words, the IC run-length distribution is robust by definition and thus all IC characteristics such as the false alarm rate $(F A R)$ and the $A R L$ would all remain the same for all continuous distributions.

\section{Out-of-control chart performance comparisons}

For the OOC chart performance comparison it is customary to ensure that the $A R L_{0}$ values of the competing charts are fixed at (or very close to) an acceptably high value, such as 500 in this case, and then compare their out-of-control $A R L$ 's i.e. their $A R L_{\delta}$ values, for specific values of the shift $\delta$; the chart with the smaller $A R L_{\delta}$ value is generally preferred. Tables 2 to 8 show the IC and OOC performance characteristics of the run-length distribution for various distributions and shifts $\delta=\gamma \frac{\sigma}{\sqrt{n}}$, where $\sigma$ denotes the process standard deviation, $\gamma$ $=0.00(0.05) 0.25,0.50,0.75,1.00,1.50,2.00$ and 3.00 , represents the shift in the median, for $m=100$ and $n=5$, for the EWMA-EX, EWMA- $\bar{X}$ and EWMA-Rank charts, respectively. The first row of each cell in Tables 2 to 8 shows the $A R L_{0}$ followed by the corresponding $S D R L_{0}$ in parentheses, whereas the second row shows the values of the IC $5^{\text {th }}, 25^{\text {th }}, 50^{\text {th }}, 75^{\text {th }}$ and $95^{\text {th }}$ percentiles (in this order).

$$
\begin{aligned}
& <\text { Insert Tables 2-8> } \\
& <\text { Insert Figures } 3 \text { - 9> }
\end{aligned}
$$

A summary of our observations from the OOC comparisons for the standard normal distribution using Table 2 and Figures $3 \mathrm{a}$ and $3 \mathrm{~b}$ is as follows:

- For all shifts under consideration the EWMA- $\bar{X}$ and EWMA-Rank charts perform similarly and both charts outperform the proposed chart. It isn't surprizing that the EWMA- $\bar{X}$ is superior to the proposed chart in this case, since it is typical for parametric methods to outperform their nonparametric counterparts when all assumptions are met.

A summary of our observations from the OOC comparisons for $\operatorname{EXP(1)}$ distribution using Table 3 and Figures $4 \mathrm{a}$ and $4 \mathrm{~b}$ is as follows:

- For all shifts under consideration the EWMA- $\bar{X}$ chart performs the worst, except for large shifts $(\gamma=1.50,2.00$ and 3.00) where the performance of the three charts are very similar. 
- Although the EWMA-Rank chart outperforms the proposed chart for shifts of $\gamma=0.50$, 0.75 and 1.00 , the performances are very similar for shifts of $\gamma=0.20$ and 0.25 and the proposed chart performs the best for small shifts of $\gamma<0.20$.

A summary of our observations from the OOC comparisons for $D E(0,1)$, the double exponential distribution, using Table 4 and Figures $5 \mathrm{a}$ and $5 \mathrm{~b}$ is as follows:

- The proposed chart outperforms the EWMA- $\bar{X}$ chart for all shifts under consideration, except for $\gamma=0.05$ where the performance is very similar and for $\gamma \geq 1.50$ where the EWMA- $\bar{X}$ performs the best.

- Although the performance for the EWMA-Rank chart and the proposed chart is very similar for shifts of sizes $\gamma \leq 0.15$ and $\gamma \geq 0.75$, the proposed chart detects shifts faster for $\gamma=0.20,0.25$ and 0.50 .

- When comparing the two competing charts, i.e. the EWMA- $\bar{X}$ and the EWMA-Rank, we find that the EWMA-Rank chart outperforms the EWMA- $\bar{X}$ chart for all shifts under consideration, except for $\gamma=0.05,2.00$ and 3.00 where the performance is very similar.

A summary of our observations from the OOC comparisons for the Symmetric Mixture Normal distribution $\left[0.6 N\left(\mu_{1}=0, \sigma_{1}=0.25\right)+0.4 N\left(\mu_{2}=0, \sigma_{2}=4\right)\right]$ using Table 5 and Figures $6 \mathrm{a}$ and $6 \mathrm{~b}$ is as follows:

- The proposed chart outperforms the EWMA- $\bar{X}$ chart for all shifts under consideration, except for $\gamma=3.00$ where the performance is very similar.

- Although the performance for the EWMA-Rank chart and the proposed chart is very similar for shift of sizes $\gamma \geq 0.50$, the proposed chart detects shifts faster for smaller shifts.

- When comparing the two competing charts, i.e. the EWMA- $\bar{X}$ and the EWMA-Rank, we find that the latter performs the best for all shifts under consideration, except for large shifts $(\gamma=3.00)$ where the performance is very similar.

Similar conclusions can be drawn for the two Asymmetric Mixture Normal distributions (see Tables 6 and 7 and Figs. 7a, 7b, 8a and 8b).

A summary of our observations from the OOC comparisons for the Log-Logistic distribution using Table 8 and Figures $9 \mathrm{a}$ and $9 \mathrm{~b}$ is as follows:

- The run-length characteristics can't be computed for the EWMA- $\bar{X}$ chart based on normal theory methods, since the run-length characteristics don't converge. This is a 
common result for control charts based on normal theory methods (see, for example, Chakraborti et al. (2004) page 454 where a similar problem is encountered for the uniform distribution when working with the Shewhart- $\bar{X}$ chart).

- Although the performance for the EWMA-Rank chart and the proposed chart is very similar, the EWMA-Rank outperforms the proposed chart for $\gamma \geq 0.15$ and the opposite is true for $\gamma<0.15$.

Thus in comparison with the EWMA- $\bar{X}$ chart, when small shifts are of interest, the proposed nonparametric chart is outperformed only when the underlying distribution is normal. However, the point to remember is that the EWMA- $\bar{X}$ chart can be non-robust in case normality is not satisfied, whereas the nonparametric chart requires no distributional assumption, which is a substantial practical advantage. In comparison with the EWMA-Rank chart, the performance of the two nonparametric charts are either similar or the proposed chart has superior performance. These observations coupled with the fact that the EWMA charts are generally easier to be used on the job floor and they provide one-chart monitoring for twosided (both higher and lower shifts) monitoring make the proposed chart a useful tool for the data analyst.

It may be noted that there is some bias in the $A R L$ (the $A R L_{\delta}$ is bigger than the $A R L_{0}$ ) of the charts for the exponential distribution when the shift is small. The bias is most prominent for the EWMA- $\bar{X}$ chart but is also slightly present in both the nonparametric charts but to a lesser extent for the proposed chart. This may be due to many extreme long run-lengths observed in the simulation of the $A R L$, which can be a result of the right-skewness of the exponential distribution coupled with the fact that the run-length distribution is itself highly right-skewed with a long right tail. The bias could also be a result of simulation error because these $A R L_{\delta}$ values are very close to the $A R L_{0}$ values. Some authors have considered $A R L-$ unbiased parametric charts and this would be a topic of further research in the context of nonparametric charts. On the other hand, Steiner and Jones (2010), among others, have recommended examining the median run-length instead "which is easier to simulate and gives arguably a better summary." This might also be an approach to consider.

\section{Effect of reference sample size}

The proposed control chart is calibrated to achieve an $A R L_{0}$ equal to a target, say 500 . However, this is the unconditional IC average run-length (averaged over all possible IC Phase I samples) and users in practice may be interested in the $A R L_{0}$ depending (conditional) on the Phase I sample they have. The attained $A R L_{0}$ will vary, since the Phase I sample is a random 
sample, even though the chart may have been designed for a nominal $A R L_{0}$ of 500 and the Phase I sample is from an IC process.

A simulation study was conducted to investigate the effect of the reference sample size on the performance of the proposed chart. The reference sample size $(m)$ was chosen to be 20 , $50,100,500$ and 1000 , respectively. The smoothing constant was taken to be 0.05 , i.e. $\lambda=$ 0.05 , and $L$ was chosen so that $A R L_{0} \approx 500$ for each reference sample size. The reference sample size with the smaller $A R L_{\delta}$ value is generally preferred. Table 9 shows the IC and OOC performance characteristics of the run-length distribution for shifts of size $\gamma=0.00(0.25) 1.00$, $1.50,2.00$ and 3.00 in the median, for the different reference sample sizes and $n=5$, for the EWMA-EX chart under the $N(0,1)$ distribution. In addition, the results are shown for the nonparametric EWMA chart based on the sign statistic (see Graham et al. (2011a)), since this is the analogue of the proposed chart if the process parameters were known or specified. The first row of each cell in Table 9 shows the $A R L_{0}$ followed by the corresponding $S D R L_{0}$ in parentheses, whereas the second row shows the values of the IC $5^{\text {th }}, 25^{\text {th }}, 50^{\text {th }}, 75^{\text {th }}$ and $95^{\text {th }}$ percentiles (in this order). The $A R L$ values are illustrated in Figure 10.

$<$ Insert Table 9>

From Table 9 and Figure 10 we find that as it might be expected, the larger the reference sample size, the less the uncertainty and the better the performance of the chart. Generally, when the reference sample size is not less than 100 , the proposed chart performs well, that is it performs like what is expected unconditionally. In addition, the values, when the parameters are unknown, tend to the values if the parameters were known, which is expected, since the uncertainty decreases as the reference sample size increases. Similar conclusions were found for other (skewed and heavy-tailed) distributions; these results were omitted here to conserve space.

$<$ Insert Figure 10>

\section{Concluding remarks}

EWMA charts take advantage of the sequentially (time ordered) accumulating nature of the data arising in a typical Statistical Process Control (SPC) environment and are known to be more efficient in detecting smaller shifts. The traditional parametric EWMA- $\bar{X}$ chart can lack in-control robustness and as such the corresponding false alarm rates can be a practical concern. Nonparametric EWMA charts offer an attractive alternative in such situations as they combine the inherent advantages of nonparametric charts (IC robustness) with the better small shift detection capability of EWMA-type charts. We propose a two-sided nonparametric Phase 
II EWMA chart based on the exceedance statistics (denoted EWMA-EX) for detecting a shift in the unknown location parameter of a continuous distribution. A performance comparison of the EWMA-EX chart is done with its competitors: the traditional parametric CUSUM and EWMA charts for subgroup averages and some nonparametric charts i.e. CUSUM and EWMA charts based on the Wilcoxon-Mann-Whitney statistics, respectively. It is seen that the EWMA-EX chart performs as well as and, in many cases, better than its competitors, particularly for distributions that are heavier-tailed and more peaked than the normal. Thus the proposed chart can be a useful tool for the quality data analyst. Finally, as a referee has noted, the choice of the reference sample order statistic is an interesting question. In this paper we have focussed on the median since it is a good representative of the central reference value for distributions of all shapes and is by far the most popular percentile used in practice. However, in general, the exceedance statistic and hence the EWMA-EX chart can be based on other percentiles (order statistics) of the reference sample and their development would follow along similar lines. This is currently being investigated and will be reported in a separate paper.

\section{Acknowledgements}

This research was supported in part by the South African Research Chairs Initiative at the University of Pretoria and by the Department of Information Systems, Statistics and Management Science, University of Alabama. A major part of the work of the second author was done during his stay at the Department of Mathematics and System Analysis, Aalto University, School of Science, Finland. Remarks and comments by the associate editor and two anonymous referees are gratefully acknowledged.

\section{References}

Balakrishnan, N. and Ng, H.K.T. (2006).Precedence-type tests and applications, John Wiley and Sons, Hoboken, New Jersey.

Borror, C.M., Montgomery, D.C. and Runger, G.C. (1999)."Robustness of the EWMA control chart to non-normality." Journal of Quality Technology, 31 (3), 309-316.

Brook, D. and Evans, D.A. (1972). "An approach to the probability distribution of CUSUM run length.” Biometrika, 59 (3), 539-549.

Chakraborti, S. and Graham, M.A. (2007). "Nonparametric control charts." Encyclopedia of Statistics in Quality and Reliability, 1, 415 - 429, John Wiley, New York.

Chakraborti, S., Human, S.W. and Graham, M.A. (2011)."Nonparametric (Distribution-Free) Quality Control Charts." In Handbook of Methods and Applications of Statistics: Engineering, Quality Control, and Physical Sciences. N. Balakrishnan, Ed., pp. 298-329. John Wiley \& Sons, New York. 
Chakraborti, S., Van der Laan, P. and Bakir, S.T. (2001). "Nonparametric control charts: An overview and some results." Journal of Quality Technology,33 (3), 304-315.

Chakraborti, S., Van der Laan, P. and Van de Wiel, M.A. (2004). "A class of distribution-free control charts." Journal of the Royal Statistical Society. Series C: Applied Statistics, 53 (3), 443-462.

Fu, J.C. and Lou, W.Y.W. (2003).Distribution Theory of Runs and Patterns and Its Applications: A Finite Markov Chain Imbedding Approach. Singapore: World Scientific Publishing.

Graham, M.A., Chakraborti, S. and Human, S.W. (2011a). "A nonparametric EWMA sign chart for location based on individual measurements." Quality Engineering, 23 (3), 227-241.

Graham, M.A., Chakraborti, S. and Human, S.W. (2011b). "A nonparametric exponentially weighted moving average signed-rank chart for monitoring location." Computational Statistics and Data Analysis, 55 (8), 2490-2503.

Graham, M.A., Human, S.W. and Chakraborti, S. (2009). "A nonparametric EWMA control chart based on the sign statistic." Technical report, 09/04, Department of Statistics, University of Pretoria, Pretoria, South Africa, ISBN 978-1-86854-777-7.

Human, S.W., Kritzinger, P. and Chakraborti, S. (2011)."Robustness of the EWMA control chart for individual observations". Journal of Applied Statistics, 38 (10), 2071-2087.

Huwang, L., Huang, C.-J. and Wang, Y.-H.T. (2010). "New EWMA control charts for monitoring process dispersion." Computational Statistics \& Data Analysis, 54 (10), 23282342.

Kantam, R.R.L. and Rao, G.S. (2005). "Cumulative sum control chart for log-logistic distribution." InterStat: Statistics on the Internet, 7, 1-9.

Li, S.Y., Tang, L.C. and Ng, S.H. (2010). "Nonparametric CUSUM and EWMA control charts for detecting mean shifts.” Journal of Quality Technology, 42 (2), 209-226.

Lucas, J.M. and Saccucci, M.S. (1990)."Exponentially weighted moving average control schemes: Properties and enhancements."Technometrics, 32 (1), 1-12.

Maravelakis, P.E. and Castagliola, P. (2009). "An EWMA chart for monitoring the process standard deviation when parameters are estimated." Computational Statistics \& Data Analysis, 53,2653-2664.

Meeker, W.Q. and Escobar, L.A. (1998). Statistical Methods for Reliability Data, John Wiley, New York, NY.

Montgomery, D.C. (2001). Introduction to Statistical Quality Control, $4^{\text {th }}$ ed., John Wiley, New York, NY.

Montgomery, D.C. (2009). Statistical Quality Control: A Modern Introduction, $6^{\text {th }}$ ed., John Wiley, New York, NY. 
Mukherjee, A., Graham, M.A. and Chakraborti, S. (2012). "Distribution-free exceedance CUSUM control charts for location." Communications in Statistics - Simulation and Computation, To Appear.

Roberts, S.W. (1959). "Control chart tests based on geometric moving averages." Technometrics, 1 (3), 239-250.

Ruggeri, F., Kenett, R.S. and Faltin, F.W. (2007).“Exponentially weighted moving average (EWMA) control chart." Encyclopedia of Statistics in Quality and Reliability, 2, 633-639, John Wiley, New York.

Steiner, S.H. and Jones, M. (2010). "Risk-adjusted survival time monitoring with an updating exponentially weighted moving average (EWMA) control chart." Statistics in Medicine, 29, 444-454.

Su, Y., Shu, L. and Tsui, K.-L.(2011). "Adaptive EWMA procedures for monitoring processes subject to linear drifts," Computational Statistics \& Data Analysis, 55(10), 2819-2829.

\section{Appendix A. Some mathematical results}

\section{The conditional IC expected value of the plotting statistic}

$E\left(Z_{j} \mid X_{(r)}\right)$

$=E\left(\lambda U_{j, r}+(1-\lambda) Z_{j-1} \mid X_{(r)}\right)$

$=E\left(\lambda \sum_{k=0}^{j-1}(1-\lambda)^{k} U_{j-k, r}+(1-\lambda)^{j} Z_{0} \mid X_{(r)}\right)$ from recursive substitution

$=n p_{r}\left(1-(1-\lambda)^{j}\right)+n p_{r}(1-\lambda)^{j}=n p_{r}$ by using properties of expected values and a geometric series together with the fact that $E\left(U_{j-k, r} \mid X_{(r)}\right)=n p_{r} \forall j, k$ and $Z_{0}=n p_{r}$.

\section{The conditional IC variance and standard deviation of the plotting statistic}

$\operatorname{VAR}\left(Z_{j} \mid X_{(r)}\right)$

$=\operatorname{VAR}\left(\lambda \sum_{k=0}^{j-1}(1-\lambda)^{k} U_{j-k, r}+(1-\lambda)^{j} Z_{0} \mid X_{(r)}\right)$ from recursive substitution

$=n p_{r}\left(1-p_{r}\right) \lambda^{2}\left(\frac{1-(1-\lambda)^{2 j}}{1-(1-\lambda)^{2}}\right)$ by using properties of variance and a geometric series along with the fact that $\operatorname{VAR}\left(U_{j-k, r} \mid X_{(r)}\right)=n p_{r}\left(1-p_{r}\right)$. The last expression simplifies to $n p_{r}(1-$ $\left.p_{r}\right) \lambda\left(\frac{1-(1-\lambda)^{2 j}}{2-\lambda}\right)$ so that $\operatorname{STDEV}\left(Z_{j} \mid X_{(r)}\right)=\sqrt{\frac{\lambda}{2-\lambda}\left(1-(1-\lambda)^{2 j}\right) n p_{r}\left(1-p_{r}\right)}$. 
The unconditional IC expected value, variance and standard deviation of the plotting statistic:

In the IC case $F\left(X_{(r)}\right)=1-p_{r}$ follows a Beta distribution with parameters $r$ and $m+1-r$. Hence, $E\left(p_{r}\right)=\frac{m+1-r}{m+1}, \operatorname{var}\left(p_{r}\right)=\frac{r(m+1-r)}{(m+1)^{2}(m+2)}$ and $E\left(p_{r}^{2}\right)=\frac{m^{2}+3 m+2-2 r m-3 r+r^{2}}{(m+1)(m+2)}$ so that $E\left(p_{r}\right)-E\left(p_{r}^{2}\right)=\frac{r(m+1-r)}{(m+1)(m+2)}$. Thus,

$$
\operatorname{var}\left(Z_{j}\right)=\operatorname{var}\left[E\left(Z_{j} \mid X_{(r)}\right)\right]+E\left[\operatorname{var}\left(Z_{j} \mid X_{(r)}\right)\right]
$$$$
=\operatorname{var}\left[n p_{r}\left(1-(1-\lambda)^{j}\right)\right]+E\left[\frac{\lambda}{2-\lambda}\left(1-(1-\lambda)^{2 j}\right) n p_{r}\left(1-p_{r}\right)\right]
$$$$
=n^{2} \frac{r(m-r+1)}{(m+1)^{2}(m+2)}\left(1-(1-\lambda)^{j}\right)^{2}+\frac{\lambda}{2-\lambda}\left(1-(1-\lambda)^{2 j}\right) n \frac{r(m-r+1)}{(m+1)(m+2)}
$$$$
=n^{2} \frac{r(m-r+1)}{(m+1)(m+1)(m+2)}\left(1-(1-\lambda)^{j}\right)^{2}+\frac{\lambda}{2-\lambda}\left(1-(1-\lambda)^{2 j}\right) n \frac{r(m-r+1)}{(m+1)(m+2)}
$$$$
=n \frac{a(1-a)}{(m+2)}\left\{n\left(1-(1-\lambda)^{j}\right)^{2}+\frac{\lambda(m+1)}{2-\lambda}\left(1-(1-\lambda)^{2 j}\right)\right\}
$$

when the process is IC, where $a=r /(m+1)$.

\section{Appendix B. Markov chain approach}

Brook and Evans (1972) introduced a Markov chain approach for computing the runlength distribution of a traditional CUSUM chart. They proposed that for a discrete monitoring statistic (for example, a count) the values that the monitoring statistic can obtain within the control limits be treated as transient states of a Markov chain, whereas all values that fall outside the limits be treated as one absorbing state. Mukherjee et al. (2012) used their approach for obtaining the conditional $A R L$ of a Phase II nonparametric CUSUM chart based on the exceedance statistics and further extended the idea to propose algorithms for computing the unconditional $A R L$ of the same chart.

Lucas and Saccucci (1990) used a similar procedure as in Brook and Evans (1972) for computing the $A R L$ of an EWMA chart by discretizing the area within the control limits into $v$ subintervals of width $2 \tau$ (resulting in $v$ transient states, say, $-s,-s+1, \ldots, s-1$, s with $v=2 s+1)$ and treating the area outside of the limits as one region (the absorbing state). As a result, the state space consists of two types of states: (i) one absorbing state (i.e. this state is entered if the chart signals) and, (ii) $v$ transient or non-absorbing states (i.e. those states for which the number of steps before the chain returns to this state is uncertain which means that the chart does not signal and hence the charting procedure continues). So, in total there are ( $v+$ 
$1=2 s+2)$ states. Using the above setup, we may summarize the computational algorithm for the unconditional $A R L$ of the proposed chart in three major steps as follows:

Step 1: Obtain the $(v+1) \times(v+1)$ transition probability matrix $\boldsymbol{M}$ of the Markov chain which is given (in partitioned form) by

$$
\boldsymbol{M}=\left(\begin{array}{cc}
\boldsymbol{R} & (\boldsymbol{I}-\boldsymbol{R}) \mathbf{1} \\
\mathbf{0} & 1
\end{array}\right)
$$

where the column vector $\mathbf{1}$ of order $v$ is a sum vector, the row vector $\mathbf{0}$ is the null vector of order $v, \boldsymbol{I}$ is the identity matrix of order $v$ and the sub-matrix $\boldsymbol{R}=\boldsymbol{R}\left(X_{(r)}\right)_{v \times v}=\left[p_{i j}\right]$ for $i, j=-s,-s+1, \ldots, s-1, s$, is referred to as the essential transition probability sub-matrix. The transition probability, $p_{i j}$, is the conditional probability that the plotting statistic at time $k, Z_{k}$, lies within state $j$, given that the plotting statistic at time $k-1, Z_{k-1}$, lies within state $i$ (an approximation to the latter probability is obtained by setting $Z_{k-1}$ equal to $S_{i}$ which denotes the midpoint of state $i$ ), that is

$$
\begin{aligned}
p_{i j}= & P\left(Z_{k} \text { lies within state } j \mid Z_{k-1} \text { lies within state } i ; X_{(r)}=x_{(r)}\right) \\
& =P\left(S_{j}-\tau<Z_{k} \leq S_{j}+\tau \mid Z_{k-1}=S_{i} ; X_{(r)}=x_{(r)}\right) \\
= & P\left(\frac{\left(S_{j}-\tau\right)-(1-\lambda) S_{i}}{\lambda}<U_{k, r} \leq \frac{\left(S_{j}+\tau\right)-(1-\lambda) S_{i}}{\lambda} \mid X_{(r)}=x_{(r)}\right) .
\end{aligned}
$$

Step 2: Using results from $\mathrm{Fu}$ and Lou (2003), calculate the conditional $A R L$ the of run-length variable $\quad N$ for a given $X_{(r)}$ given by $E\left(N \mid X_{(r)}\right)=\boldsymbol{p}^{\boldsymbol{T}}(\boldsymbol{I}-\boldsymbol{R}) \mathbf{1} \quad$ where $\boldsymbol{p}^{\boldsymbol{T}}=\left(p_{-s}, p_{-s+1}, \ldots, p_{s-1}, p_{s}\right)$ is the initial transition probability vector with $p_{j}$ being the probability that $Z$ starts at state $j$. For the IC case, the $p_{i j}$ 's are calculated assuming the process is IC which yields the conditional IC $A R L$.

Step 3: The unconditional $A R L$ of $N$ is given by averaging the conditional $A R L$ over the probability distribution of $X_{(r)}$. Thus, the unconditional average run-length is given by

$$
\mu^{*}=E E\left(N \mid X_{(r)}\right)=\int E\left(N \mid X_{(r)}\right) d F\left(X_{(r)}\right)=\int \mu d V_{(r)}, \text { say. }
$$

In the IC case, this may be approximated by applying numerical integration as in Mukherjee et al. (2012) using the relation

$$
A R L_{0}=\mu^{*}(\mathrm{IC})=\lim _{l \rightarrow 0} \sum_{\xi}\left(\mu \mid p_{r}=\xi, \mathrm{IC}\right) \int_{\xi-\frac{l}{2}}^{\xi+\frac{l}{2}} \frac{1}{B(r, m-r+1)} y^{r-1}(1-y)^{m-r} d y,
$$

where $\xi$ ranges from $a-l / 2$ to $b+l / 2$ in steps of $l, l$ is a small positive proper fraction, $a$ and $b$ are such that $0<a<b<1$, satisfying 


$$
\int_{0}^{\mathrm{a}} \mu d V_{(r)} \cong 0 \text { and } \int_{\mathrm{b}}^{1} \mu d V_{(r)} \cong 0
$$

The IC conditional mean in the above expression $\left(\mu \mid p_{r}=\xi\right.$, IC), can be calculated using the Markov chain formula in (3) in Mukherjee et al. (2012). Details are omitted here.

Expressions for the conditional and unconditional run-length distributions can be obtained quite similarly using properties and results of Markov chains (see Fu and Lou (2003)), from which other run-length distribution characteristics such as the standard deviation and the percentiles can be found. Details are omitted for brevity.

\section{Appendix C. Simulation algorithm}

Step 1: After specifying the distribution, the IC parameters, the reference sample size, the test sample (subgroup) size, the size of the shift to be detected, the value of $r$ and the two design parameters, $\lambda$ and $L$ (see Tables $1 \mathrm{a}$ and $1 \mathrm{~b}$ ), we generate the reference samples and compute $X_{(r)}$.

Step 2: We generate random samples of size $n$ and calculate the number of $Y$-observations in each test sample that exceeds $X_{(r)}$.

Step 3: Calculate the $U_{j, r}$ and the plotting statistic $Z_{j}$ (see equation (1)) for each subgroup.

Step 4: Calculate the steady-state control limits using equation (3) and compare $Z_{j}$ to the control limits.

Step 5: The number of subgroups needed until $Z_{j}$ plots on or outside the control limits is recorded as an observation from the run-length distribution.

Step 6: Repeat steps 1 to 5 a total of 100,000 times.

Step 7: Once we have obtained a "dataset" with 100,000 observations from the run-length distribution, proc univariate of $\mathrm{SAS}^{\circledR} \mathrm{v} 9.1 .3$ was used to obtain some descriptive statistics, the so-called run-length distribution characteristics. This includes the mean, the standard deviation and the 5th, 25th, 50th, 75th and 95th percentiles. The results were verified using $\mathrm{R}^{\circledR} \mathrm{v} 2.11 .0$. 
Table ${ }^{\text {a }}$ 1a. $(\lambda, L)$-combinations for the EWMA-EX chart for nominal $A R L_{0}=370$ and 500, respectively, for $n=5$.

\begin{tabular}{|c|c|c|c|c|c|}
\hline & \multirow{2}{*}{\multicolumn{2}{|c|}{ Nominal $A R L_{0}=370$}} & \multirow{2}{*}{\multicolumn{2}{|c|}{ Nominal $A R L_{0}=500$}} \\
\hline & & & & & \\
\hline$m$ & Shift & $(\lambda, L)$ & Attained values & $(\lambda, L)$ & Attained values \\
\hline \multirow{6}{*}{49} & \multirow{3}{*}{ Small } & $(0.01,0.570)$ & $\begin{array}{c}377.86(737.57) \\
30,57,117,326,1690 \\
\end{array}$ & $(0.01,0.615)$ & $\begin{array}{c}501.50(1102.85) \\
34,64,133,392,2298 \\
\end{array}$ \\
\hline & & $(0.025,0.964)$ & $\begin{array}{c}368.09(714.73) \\
21,46,106,343,1700 \\
\end{array}$ & $(0.025,1.015)$ & $\begin{array}{c}499.46(1037.62) \\
23,51,119,438,2327\end{array}$ \\
\hline & & $(0.05,1.351)$ & $\begin{array}{c}372.86(667.30) \\
17,42,110,379,1692\end{array}$ & $(0.05,1.411)$ & $\begin{array}{c}499.94(925.83) \\
19,48,136,507,2250\end{array}$ \\
\hline & Moderate & $(0.10,1.816)$ & $\begin{array}{c}369.39(605.82) \\
14,43,131,415,1522 \\
\end{array}$ & $(0.10,1.884)$ & $\begin{array}{c}501.49(849.82) \\
16,51,168,552,2174 \\
\end{array}$ \\
\hline & \multirow{2}{*}{ Large } & $(0.20,2.255)$ & $\begin{array}{c}369.16(555.17) \\
12,50,160,457,1421\end{array}$ & $(0.20,2.319)$ & $\begin{array}{c}504.22(756.62) \\
14,64,208,622,2028\end{array}$ \\
\hline & & $(0.25,2.365)$ & $\begin{array}{c}374.26(531.26) \\
12,55,171,468,1425\end{array}$ & $(0.25,2.429)$ & $\begin{array}{c}503.62(734.34) \\
14,70,224,625,1958\end{array}$ \\
\hline \multirow{6}{*}{99} & \multirow{3}{*}{ Small } & $(0.01,0.736)$ & $\begin{array}{c}374.78(619.80) \\
37,73,150,374,1554\end{array}$ & $(0.01,0.794)$ & $\begin{array}{c}500.56(901.65) \\
41,84,174,486,2094 \\
\end{array}$ \\
\hline & & $(0.025,1.222)$ & $\begin{array}{c}370.20(583.49) \\
27,63,149,418,1496 \\
\end{array}$ & $(0.025,1.289)$ & $\begin{array}{c}498.82(823.42) \\
30,74,180,542,2107\end{array}$ \\
\hline & & $(0.05,1.669)$ & $\begin{array}{c}368.29(546.03) \\
22,61,160,442,1406 \\
\end{array}$ & $(0.05,1.743)$ & $\begin{array}{c}499.61(804.97) \\
24,70,188,560,2115 \\
\end{array}$ \\
\hline & Moderate & $(0.10,2.132)$ & $\begin{array}{c}372.93(519.76) \\
18,63,176,460,1387\end{array}$ & $(0.10,2.211)$ & $\begin{array}{c}500.07(698.94) \\
21,77,231,630,1861 \\
\end{array}$ \\
\hline & \multirow{2}{*}{ Large } & $(0.20,2.499)$ & $\begin{array}{c}371.69(474.05) \\
16,73,199,483,1303 \\
\end{array}$ & $(0.20,2.577)$ & $\begin{array}{c}500.06(648.69) \\
19,92,263,650,1788\end{array}$ \\
\hline & & $(0.25,2.579)$ & $\begin{array}{c}369.88(457.96) \\
16,76,207,485,1281 \\
\end{array}$ & $(0.25,2.655)$ & $\begin{array}{c}501.47(631.49) \\
19,98,275,659,1758 \\
\end{array}$ \\
\hline \multirow{6}{*}{149} & \multirow{3}{*}{ Small } & $(0.01,0.846)$ & $\begin{array}{c}370.79(534.05) \\
40,83,172,417,1418 \\
\end{array}$ & $(0.01,0.914)$ & $\begin{array}{c}502.33(785.51) \\
45,97,207,541,1979\end{array}$ \\
\hline & & $(0.025,1.381)$ & $\begin{array}{c}371.71(529.02) \\
30,74,170,439,1408\end{array}$ & $(0.025,1.465)$ & $\begin{array}{c}500.03(750.52) \\
34,87,209,574,1992\end{array}$ \\
\hline & & $(0.05,1.847)$ & $\begin{array}{c}379.76(519.83) \\
25,73,187,467,1411 \\
\end{array}$ & $(0.05,1.927)$ & $\begin{array}{c}501.17(715.41) \\
28,84,229,621,1884\end{array}$ \\
\hline & Moderate & $(0.10,2.289)$ & $\begin{array}{c}371.18(471.05) \\
21,75,200,481,1292 \\
\end{array}$ & $(0.10,2.375)$ & $\begin{array}{c}499.46(649.81) \\
24,95,256,648,1784 \\
\end{array}$ \\
\hline & \multirow{2}{*}{ Large } & $(0.20,2.599)$ & $\begin{array}{c}369.58(436.17) \\
19,84,217,491,1240 \\
\end{array}$ & $(0.20,2.684)$ & $\begin{array}{c}500.59(603.06) \\
22,108,289,665,1693 \\
\end{array}$ \\
\hline & & $(0.25,2.638)$ & $\begin{array}{c}373.83(479.07) \\
18,76,217,488,1111 \\
\end{array}$ & $(0.25,2.752)$ & $\begin{array}{c}499.95(579.65) \\
8,159,314,679,1508 \\
\end{array}$ \\
\hline
\end{tabular}

${ }^{\text {a }}$ Note that the first row of each cell shows the $A R L$ followed by the corresponding $S D R L$ in parentheses, whereas the second row shows the values of the $5^{\text {th }}, 25^{\text {th }}, 50^{\text {th }}, 75^{\text {th }}$ and $95^{\text {th }}$ percentiles (in this order). 
Table $^{\mathbf{b}}$ 1b. $(\lambda, L)$-combinations for the EWMA-EX chart for nominal $A R L_{0}=370$ and 500, respectively, for $n=10$.

\begin{tabular}{|c|c|c|c|c|c|}
\hline & & Nom & I $A R L_{0}=370$ & Nom & $A R L_{0}=500$ \\
\hline$m$ & Shift & $(\lambda, L)$ & Attained values & $(\lambda, L)$ & Attained values \\
\hline \multirow{6}{*}{49} & \multirow{3}{*}{ Small } & $(0.01,0.439)$ & $\begin{array}{c}371.73(968.91) \\
23,43,83,232,1774\end{array}$ & $(0.01,0.467)$ & $\begin{array}{c}505.47(1394.73) \\
25,47,94,278,2436\end{array}$ \\
\hline & & $(0.025,0.738)$ & $\begin{array}{c}371.73(897.38) \\
17,33,73,253,1856 \\
\end{array}$ & $(0.025,0.771)$ & $\begin{array}{c}505.61(1315.01) \\
17,36,81,309,2590\end{array}$ \\
\hline & & $(0.05,1.060)$ & $\begin{array}{c}369.96(818.33) \\
13,29,73,294,1836\end{array}$ & $(0.05,1.100)$ & $\begin{array}{c}499.59(1164.46) \\
14,31,86,381,2516 \\
\end{array}$ \\
\hline & Moderate & $(0.10,1.466)$ & $\begin{array}{c}369.85(737.47) \\
10,27,86,346,1771 \\
\end{array}$ & $(0.10,1.516)$ & $\begin{array}{c}499.08(1036.26) \\
11,31,103,454,2430\end{array}$ \\
\hline & \multirow{2}{*}{ Large } & $(0.20,1.930)$ & $\begin{array}{c}370.80(656.18) \\
9,33,114,396,1672\end{array}$ & $(0.20,1.991)$ & $\begin{array}{c}501.73(904.94) \\
9,37,144,540,2240\end{array}$ \\
\hline & & $(0.25,2.074)$ & $\begin{array}{c}370.28(619.28) \\
8,35,127,425,1570 \\
\end{array}$ & $(0.25,2.135)$ & $\begin{array}{c}499.48(876.21) \\
9,41,156,554,2175\end{array}$ \\
\hline \multirow{6}{*}{99} & \multirow{3}{*}{ Small } & $(0.01,0.571)$ & $\begin{array}{c}371.25(750.94) \\
29,57,113,315,1676\end{array}$ & $(0.01,0.610)$ & $\begin{array}{c}503.98(1119.20) \\
32,63,129,381,2375\end{array}$ \\
\hline & & $(0.025,0.959)$ & $\begin{array}{c}368.36(713.91) \\
21,46,105,341,1669\end{array}$ & $(0.025,1.010)$ & $\begin{array}{c}499.54(1033.34) \\
24,52,124,446,2380\end{array}$ \\
\hline & & $(0.05,1.355)$ & $\begin{array}{c}370.29(664.74) \\
17,42,113,385,1640 \\
\end{array}$ & $(0.05,1.413)$ & $\begin{array}{c}504.63(967.66) \\
18,48,137,493,2320 \\
\end{array}$ \\
\hline & Moderate & $(0.10,1.812)$ & $\begin{array}{c}373.22(617.30) \\
14,43,133,426,1553 \\
\end{array}$ & $(0.10,1.880)$ & $\begin{array}{c}503.75(857.94) \\
15,50,166,561,2164 \\
\end{array}$ \\
\hline & \multirow{2}{*}{ Large } & $(0.20,2.266)$ & $\begin{array}{c}369.89(542.58) \\
12,51,161,455,1456\end{array}$ & $(0.20,2.338)$ & $\begin{array}{c}500.76(756.93) \\
14,63,207,611,1997\end{array}$ \\
\hline & & $(0.25,2.390)$ & $\begin{array}{c}369.52(519.03) \\
12,55,171,464,1412\end{array}$ & $(0.25,2.463)$ & $\begin{array}{c}503.83(728.69) \\
14,70,224,629,1944 \\
\end{array}$ \\
\hline \multirow{6}{*}{149} & \multirow{3}{*}{ Small } & $(0.01,0.665)$ & $\begin{array}{c}368.63(642.38) \\
34,68,137,357,1542 \\
\end{array}$ & $(0.01,0.713)$ & $\begin{array}{c}507.72(986.88) \\
37,74,156,449,2302 \\
\end{array}$ \\
\hline & & $(0.025,1.114)$ & $\begin{array}{c}369.96(634.85) \\
24,55,131,388,1570 \\
\end{array}$ & $(0.025,1.166)$ & $\begin{array}{c}498.48(926.18) \\
27,61,152,476,2198 \\
\end{array}$ \\
\hline & & $(0.05,0.541)$ & $\begin{array}{c}369.08(585.76) \\
19,52,138,424,1509\end{array}$ & $(0.05,1.604)$ & $\begin{array}{c}498.30(850.32) \\
21,58,167,549,2132 \\
\end{array}$ \\
\hline & Moderate & $(0.10,2.010)$ & $\begin{array}{c}371.881(630.48) \\
17,49,148,425,1364\end{array}$ & $(0.10,2.082)$ & $\begin{array}{c}503.22(751.75) \\
18,66,204,610,2009\end{array}$ \\
\hline & \multirow{2}{*}{ Large } & $(0.20,2.434)$ & $\begin{array}{c}372.19(494.57) \\
14,64,184,479,1377 \\
\end{array}$ & $(0.20,2.508)$ & $\begin{array}{c}508.27(691.98) \\
17,83,241,644,1919 \\
\end{array}$ \\
\hline & & $(0.25,2.534)$ & $\begin{array}{c}372.30(482.97) \\
15,69,195,489,1335\end{array}$ & $(0.25,2.613)$ & $\begin{array}{c}500.23(659.88) \\
17,87,259,649,1808\end{array}$ \\
\hline
\end{tabular}

${ }^{\mathrm{b}}$ Note that the first row of each cell shows the $A R L$ followed by the corresponding $S D R L$ in parentheses, whereas the second row shows the values of the $5^{\text {th }}, 25^{\text {th }}, 50^{\text {th }}, 75^{\text {th }}$ and $95^{\text {th }}$ percentiles (in this order). 
Table $^{\mathfrak{c}}$ 2. Control chart performance comparison under the $N(0,1)$ distribution for $m=100$ and $n=5$

\begin{tabular}{|c|c|c|c|c|c|c|}
\hline \multirow[b]{2}{*}{$\begin{array}{l}\text { Control } \\
\text { limits }\end{array}$} & \multicolumn{2}{|c|}{ EWMA-EX } & \multicolumn{2}{|c|}{ EWMA- $\bar{X}$} & \multicolumn{2}{|c|}{ EWMA-Rank } \\
\hline & $\begin{array}{c}1.991 ; 3.058 \\
\text { with } L=1.75\end{array}$ & $\begin{array}{c}1.735 ; 3.314 \\
\text { with } L=2.22\end{array}$ & $\begin{array}{c} \pm 0.462 \\
\text { with } L=2.855\end{array}$ & $\begin{array}{c} \pm 0.682 \\
\text { with } L=2.945\end{array}$ & $234.2 ; 295.8$ & $219.5 ; 310.5$ \\
\hline $\begin{array}{l}\text { Shift } \\
(\gamma)\end{array}$ & 0.05 & 0.10 & 0.05 & 0.10 & 0.05 & 0.10 \\
\hline 0.00 & $\begin{array}{c}508.45(795.41) \\
24,72,200,590,2106\end{array}$ & $\begin{array}{c}510.77(748.45) \\
21,78,226,624,1970\end{array}$ & $\begin{array}{c}512.42(1009.21) \\
22,64,177,534,2065\end{array}$ & $\begin{array}{c}512.30(947.37) \\
19,68,198,554,1988\end{array}$ & $\begin{array}{c}503.99(874.65) \\
23,68,189,551,2046\end{array}$ & $\begin{array}{c}512.69(851.32) \\
19,73,215,593,1998\end{array}$ \\
\hline 0.05 & $\begin{array}{c}507.91(795.12) \\
24,72,201,589,2048\end{array}$ & $\begin{array}{c}510.31(730.32) \\
21,80,233,632,1948\end{array}$ & $\begin{array}{c}499.63(998.64) \\
22,62,172,515,2034\end{array}$ & $\begin{array}{c}490.05(919.96) \\
18,64,186,529,1929\end{array}$ & $\begin{array}{c}490.07(863.99) \\
23,64,181,535,2000\end{array}$ & $\begin{array}{c}501.66(823.91) \\
19,70,206,581,1951\end{array}$ \\
\hline 0.10 & $\begin{array}{c}495.49(778.53) \\
23,68,193,573,2015\end{array}$ & $\begin{array}{c}495.01(720.90) \\
21,75,223,603,1915\end{array}$ & $\begin{array}{c}467.07(1043.25) \\
21,56,153,471,1910\end{array}$ & $\begin{array}{c}468.48(903.72) \\
16,58,171,497,1869\end{array}$ & $\begin{array}{c}462.83(828.64) \\
21,59,161,489,1930\end{array}$ & $\begin{array}{c}473.97(791.54) \\
18,64,189,539,1874\end{array}$ \\
\hline 0.15 & $\begin{array}{c}468.66(765.37) \\
22,62,176,531,1938\end{array}$ & $\begin{array}{c}477.07(706.56) \\
19,69,205,584,1875\end{array}$ & $\begin{array}{c}435.25(941.97) \\
19,50,133,415,1810\end{array}$ & $\begin{array}{c}428.09(892.92) \\
15,49,146,438,1722\end{array}$ & $\begin{array}{c}427.94(803.86) \\
20,52,140,439,1815\end{array}$ & $\begin{array}{c}437.01(778.45) \\
16,54,161,487,1772\end{array}$ \\
\hline 0.20 & $\begin{array}{c}438.12(738.95) \\
21,56,151,477,1853\end{array}$ & $\begin{array}{c}446.35(687.68) \\
17,61,182,537,1771\end{array}$ & $\begin{array}{c}371.67(822.70) \\
17,41,105,337,1608\end{array}$ & $\begin{array}{c}381.96(814.08) \\
13,41,119,377,1590\end{array}$ & $\begin{array}{c}375.46(748.86) \\
18,44,113,360,1614\end{array}$ & $\begin{array}{c}391.61(733.35) \\
15,46,134,413,1624\end{array}$ \\
\hline 0.25 & $\begin{array}{c}398.98(687.24) \\
20,49,130,417,1738\end{array}$ & $\begin{array}{c}418.13(670.26) \\
16,51,153,480,1766\end{array}$ & $\begin{array}{c}312.72(695.72) \\
15,35,82,262,1367\end{array}$ & $\begin{array}{c}324.52(734.68) \\
12,34,93,294,1389\end{array}$ & $\begin{array}{c}326.08(705.73) \\
16,37,88,287,1453\end{array}$ & $\begin{array}{c}335.53(660.36) \\
13,37,105,334,1434\end{array}$ \\
\hline 0.50 & $\begin{array}{c}185.97(456.32) \\
14,26,49,129,860\end{array}$ & $\begin{array}{c}197.19(429.69) \\
11,25,55,164,886\end{array}$ & $\begin{array}{c}93.36(305.26) \\
10,18,31,62,307\end{array}$ & $\begin{array}{c}102.24(325.86) \\
8,16,31,72,375\end{array}$ & $\begin{array}{c}98.77(306.09) \\
11,19,32,66,348\end{array}$ & $\begin{array}{c}112.62(325.32) \\
9,17,34,80,441\end{array}$ \\
\hline 0.75 & $\begin{array}{c}62.22(189.51) \\
10,17,27,48,176\end{array}$ & $\begin{array}{c}70.73(205.42) \\
8,15,26,54,238\end{array}$ & $\begin{array}{c}26.76(53.78) \\
8,12,18,27,64\end{array}$ & $\begin{array}{c}28.45(87.72) \\
6,10,16,27,78\end{array}$ & $\begin{array}{c}30.18(84.12) \\
9,13,19,29,70\end{array}$ & $\begin{array}{c}31.53(84.31) \\
6,11,17,29,87\end{array}$ \\
\hline 1.00 & $\begin{array}{c}24.76(34.77) \\
9,13,18,26,59 \\
\end{array}$ & $\begin{array}{c}28.14(63.53) \\
7,11,16,27,76 \\
\end{array}$ & $\begin{array}{c}14.81(11.84) \\
6,9,12,17,30 \\
\end{array}$ & $\begin{array}{c}13.53(13.12) \\
5,7,10,16,32\end{array}$ & $\begin{array}{c}15.90(14.64) \\
7,10,13,18,32\end{array}$ & $\begin{array}{c}14.83(19.69) \\
5,8,11,17,34\end{array}$ \\
\hline 1.50 & $\begin{array}{c}12.73(6.13) \\
7,9,11,15,23\end{array}$ & $\begin{array}{c}11.33(6.90) \\
5,7,10,13,23\end{array}$ & $\begin{array}{c}8.40(3.11) \\
5,6,8,10,14\end{array}$ & $\begin{array}{c}7.02(3.18) \\
4,5,6,8,13\end{array}$ & $\begin{array}{c}9.05(3.16) \\
5,7,8,10,15\end{array}$ & $\begin{array}{c}7.57(3.33) \\
4,5,7,9,14 \\
\end{array}$ \\
\hline 2.00 & $\begin{array}{c}9.20(2.64) \\
6,7,9,10,14 \\
\end{array}$ & $\begin{array}{c}7.69(2.73) \\
5,6,7,9,13 \\
\end{array}$ & $\begin{array}{l}6.00(1.71) \\
4,5,6,7,9 \\
\end{array}$ & $\begin{array}{l}4.85(1.63) \\
3,4,5,6,8\end{array}$ & $\begin{array}{c}6.60(1.68) \\
4,5,6,7,10 \\
\end{array}$ & $\begin{array}{l}5.34(1.62) \\
3,4,5,6,8\end{array}$ \\
\hline 3.00 & $\begin{array}{l}6.66(1.08) \\
5,6,7,7,9\end{array}$ & $\begin{array}{l}5.37(1.04) \\
4,5,5,6,7 \\
\end{array}$ & $\begin{array}{l}3.95(0.85) \\
3,3,4,4,5\end{array}$ & $\begin{array}{l}3.12(0.78) \\
2,3,3,4,4\end{array}$ & $\begin{array}{l}4.61(0.76) \\
4,4,5,5,6\end{array}$ & $\begin{array}{l}3.64(0.71) \\
3,3,4,4,5\end{array}$ \\
\hline
\end{tabular}

Table $^{\mathbf{d}}$ 3. Control chart performance comparison under the $\operatorname{EXP}(1)$ distribution for $m=100$ and $n=5$

\begin{tabular}{|c|c|c|c|c|c|c|}
\hline \multirow[b]{2}{*}{$\begin{array}{l}\text { Control } \\
\text { limits }\end{array}$} & \multicolumn{2}{|c|}{ EWMA-EX } & \multicolumn{2}{|c|}{ EWMA- $\bar{X}$} & \multicolumn{2}{|c|}{ EWMA-Rank } \\
\hline & $\begin{array}{c}1.991 ; 3.058 \\
\text { with } L=1.75\end{array}$ & $\begin{array}{c}1.735 ; 3.314 \\
\text { with } L=2.22\end{array}$ & $\begin{array}{c} \pm 0.444 \\
\text { with } L=2.745\end{array}$ & $\begin{array}{c} \pm 0.640 \\
\text { with } L=2.764\end{array}$ & $234.2 ; 295.8$ & $219.5 ; 310.5$ \\
\hline $\begin{array}{l}\text { Shift } \\
(\gamma)\end{array}$ & 0.05 & 0.10 & 0.05 & 0.10 & 0.05 & 0.10 \\
\hline 0.00 & $\begin{array}{c}503.27(784.58) \\
24,71,198,578,2000 \\
\end{array}$ & $\begin{array}{c}501.01(713.38) \\
21,78,230,630,1881\end{array}$ & $\begin{array}{c}501.57(1217.83) \\
20,58,156,456,1982\end{array}$ & $\begin{array}{c}486.29(1536.20) \\
14,50,145,422,1805\end{array}$ & $\begin{array}{c}497.86(851.89) \\
23,66,185,548,2003\end{array}$ & $\begin{array}{c}498.52(817.35) \\
19,71,206,584,1913\end{array}$ \\
\hline 0.05 & $\begin{array}{c}493.73(784.30) \\
24,69,190,572,2003\end{array}$ & $\begin{array}{c}501.15(718.26) \\
20,76,225,623,1923\end{array}$ & $\begin{array}{c}594.59(2362.45) \\
18,55,154,486,2224\end{array}$ & $\begin{array}{c}542.13(2195.01) \\
13,47,144,443,1973\end{array}$ & $\begin{array}{c}539.44(1006.62) \\
22,62,175,558,2309\end{array}$ & $\begin{array}{c}564.45(1018.23) \\
19,69,210,625,2256\end{array}$ \\
\hline 0.10 & $\begin{array}{c}465.72(757.07) \\
22,61,171,525,1958\end{array}$ & $\begin{array}{c}467.30(695.29) \\
19,66,197,569,1848\end{array}$ & $\begin{array}{c}626.89(2342.87) \\
16,49,142,484,2445\end{array}$ & $\begin{array}{c}568.88(2322.94) \\
11,42,132,430,2122\end{array}$ & $\begin{array}{c}535.78(1134.54) \\
19,50,139,495,2408\end{array}$ & $\begin{array}{c}584.85(1255.91) \\
16,54,172,583,2459\end{array}$ \\
\hline 0.15 & $\begin{array}{c}424.85(732.02) \\
20,52,141,459,1821\end{array}$ & $\begin{array}{c}437.76(683.18) \\
17,57,175,521,1783\end{array}$ & $\begin{array}{c}647.13(2488.89) \\
15,42,122,448,2587\end{array}$ & $\begin{array}{c}594.16(2716.43) \\
10,35,112,398,2245\end{array}$ & $\begin{array}{c}466.16(1177.47) \\
16,38,94,350,2172\end{array}$ & $\begin{array}{c}521.53(1279.31) \\
14,39,119,447,2306\end{array}$ \\
\hline 0.20 & $\begin{array}{c}384.42(702.73) \\
18,44,115,387,1700\end{array}$ & $\begin{array}{c}390.20(641.21) \\
15,46,137,439,1666\end{array}$ & $\begin{array}{c}672.79(3214.85) \\
13,36,100,376,2558\end{array}$ & $\begin{array}{c}562.16(2650.41) \\
9,30,90,334,2138\end{array}$ & $\begin{array}{c}385.49(1209.37) \\
14,30,64,218,1809\end{array}$ & $\begin{array}{c}439.17(1269.71) \\
12,29,79,302,2013\end{array}$ \\
\hline 0.25 & $\begin{array}{c}317.06(641.13) \\
16,36,86,292,1405 \\
\end{array}$ & $\begin{array}{c}341.02(619.71) \\
13,36,104,359,1476\end{array}$ & $\begin{array}{c}588.82(2131.56) \\
12,30,76,292,2441 \\
\end{array}$ & $\begin{array}{c}510.79(2293.24) \\
8,25,69,257,1946 \\
\end{array}$ & $\begin{array}{c}285.71(1263.33) \\
13,24,44,117,1153 \\
\end{array}$ & $\begin{array}{c}360.68(1456.22) \\
10,23,56,188,1553 \\
\end{array}$ \\
\hline 0.50 & $\begin{array}{c}109.14(320.47) \\
10,17,28,64,434 \\
\end{array}$ & $\begin{array}{c}113.82(317.98) \\
8,15,28,70,503 \\
\end{array}$ & $\begin{array}{l}240.42(1440.65) \\
8,16,29,67,639 \\
\end{array}$ & $\begin{array}{l}242.38(1893.71) \\
6,13,27,67,559 \\
\end{array}$ & $\begin{array}{c}48.25(410.08) \\
9,12,18,28,81 \\
\end{array}$ & $\begin{array}{c}59.77(434.05) \\
7,11,16,30,122 \\
\end{array}$ \\
\hline 0.75 & $\begin{array}{c}29.89(105.11) \\
7,11,15,23,65\end{array}$ & $\begin{array}{c}28.59(87.85) \\
6,9,13,22,79 \\
\end{array}$ & $\begin{array}{c}58.22(578.88) \\
7,11,17,28,90 \\
\end{array}$ & $\begin{array}{c}47.76(550.19) \\
5,9,15,27,105\end{array}$ & $\begin{array}{c}14.81(80.81) \\
7,9,11,15,26\end{array}$ & $\begin{array}{c}13.68(50.90) \\
5,7,10,14,28\end{array}$ \\
\hline 1.00 & $\begin{array}{c}12.74(19.09) \\
6,8,10,13,26 \\
\end{array}$ & $\begin{array}{r}11.86(36.27) \\
5,6,8,12,25 \\
\end{array}$ & $\begin{array}{c}18.10(141.41) \\
5,8,12,18,36 \\
\end{array}$ & $\begin{array}{c}16.08(49.40) \\
4,7,10,16,39 \\
\end{array}$ & $\begin{array}{c}9.36(3.69) \\
6,7,9,11,15 \\
\end{array}$ & $\begin{array}{l}8.14(14.79) \\
4,6,7,9,15 \\
\end{array}$ \\
\hline 1.50 & $\begin{array}{l}6.06(1.94) \\
5,5,5,6,9 \\
\end{array}$ & $\begin{array}{l}4.86(1.64) \\
4,4,4,5,8 \\
\end{array}$ & $\begin{array}{c}8.36(4.22) \\
4,6,7,10,15 \\
\end{array}$ & $\begin{array}{c}6.87(4.27) \\
3,4,6,8,14 \\
\end{array}$ & $\begin{array}{l}6.37(1.38) \\
5,5,6,7,9 \\
\end{array}$ & $\begin{array}{l}5.15(1.30) \\
4,4,5,6,8 \\
\end{array}$ \\
\hline 2.00 & $\begin{array}{l}5.02(0.23) \\
5,5,5,5,5\end{array}$ & $\begin{array}{l}4.02(0.21) \\
4,4,4,4,4 \\
\end{array}$ & $\begin{array}{c}5.86(2.08) \\
3,4,5,7,10\end{array}$ & $\begin{array}{l}4.61(1.88) \\
2,3,4,5,8 \\
\end{array}$ & $\begin{array}{l}5.14(0.82) \\
4,5,5,6,7 \\
\end{array}$ & $\begin{array}{l}4.08(0.74) \\
3,4,4,4,5\end{array}$ \\
\hline 3.00 & $\begin{array}{l}5.00(0.00) \\
5,5,5,5,5 \\
\end{array}$ & $\begin{array}{l}4.00(0.00) \\
4,4,4,4,4 \\
\end{array}$ & $\begin{array}{r}3.81(0.99) \\
2,3,4,4,6 \\
\end{array}$ & $\begin{array}{r}2.95(0.85) \\
2,2,3,3,4 \\
\end{array}$ & $\begin{array}{l}4.11(0.37) \\
4,4,4,4,5 \\
\end{array}$ & $\begin{array}{l}3.16(0.37) \\
3,3,3,3,4 \\
\end{array}$ \\
\hline
\end{tabular}

\footnotetext{
${ }^{\mathrm{c}}$ Note that the first row of each cell shows the $A R L$ followed by the corresponding $S D R L$ in parentheses, whereas the second row shows the values of the $5^{\text {th }}, 25^{\text {th }}, 50^{\text {th }}, 75^{\text {th }}$ and $95^{\text {th }}$ percentiles (in this order).

${ }^{\mathrm{d}}$ Note that the first row of each cell shows the $A R L$ followed by the corresponding $S D R L$ in parentheses, whereas the second row shows the values of the $5^{\text {th }}, 25^{\text {th }}, 50^{\text {th }}, 75^{\text {th }}$ and $95^{\text {th }}$ percentiles (in this order).
} 
Table $^{\mathbf{e}}$ 4. Control chart performance comparison under the $D E(0,1)$ distribution for $m=100$ and $n=5$

\begin{tabular}{|c|c|c|c|c|c|c|}
\hline \multirow[b]{2}{*}{$\begin{array}{l}\text { Control } \\
\text { limits }\end{array}$} & \multicolumn{2}{|c|}{ EWMA-EX } & \multicolumn{2}{|c|}{ EWMA- $\bar{X}$} & \multicolumn{2}{|c|}{ EWMA-Rank } \\
\hline & $\begin{array}{c}1.991 ; 3.058 \\
\text { with } L=1.75\end{array}$ & $\begin{array}{c}1.735 ; 3.314 \\
\text { with } L=2.22\end{array}$ & $\begin{array}{c} \pm 0.449 \\
\text { with } L=2.774\end{array}$ & $\begin{array}{c} \pm 0.666 \\
\text { with } L=2.875\end{array}$ & $234.2 ; 295.8$ & $219.5 ; 310.5$ \\
\hline $\begin{array}{l}\text { Shift } \\
(\gamma)\end{array}$ & 0.05 & 0.10 & 0.05 & 0.10 & 0.05 & 0.10 \\
\hline 0.00 & $\begin{array}{c}499.65(784.93) \\
24,70,197,586,2017\end{array}$ & $\begin{array}{c}500.75(735.73) \\
19,76,222,618,1937\end{array}$ & $\begin{array}{c}498.47(1367.32) \\
20,57,150,443,1962\end{array}$ & $\begin{array}{c}499.84(1655.17) \\
16,58,159,448,1812\end{array}$ & $\begin{array}{c}498.75(859.89) \\
23,68,187,551,2026\end{array}$ & $\begin{array}{c}511.47(829.81) \\
20,73,215,593,2003\end{array}$ \\
\hline 0.05 & $\begin{array}{c}498.83(787.98) \\
24,68,194,572,2033\end{array}$ & $\begin{array}{c}500.62(723.67) \\
20,76,222,617,1938\end{array}$ & $\begin{array}{c}490.13(1475.95) \\
20,56,147,427,1890\end{array}$ & $\begin{array}{c}490.21(1480.48) \\
16,55,157,449,1855\end{array}$ & $\begin{array}{c}486.51(855.26) \\
22,64,177,530,1987\end{array}$ & $\begin{array}{c}492.63(806.30) \\
19,69,204,569,1944\end{array}$ \\
\hline 0.10 & $\begin{array}{c}452.16(748.64) \\
22,61,166,502,1867\end{array}$ & $\begin{array}{c}458.28(682.42) \\
19,68,196,554,1796\end{array}$ & $\begin{array}{c}461.25(1291.09) \\
19,51,135,403,1801\end{array}$ & $\begin{array}{c}482.16(1520.52) \\
15,51,146,427,1805\end{array}$ & $\begin{array}{c}446.37(815.47) \\
20,56,152,473,1852\end{array}$ & $\begin{array}{c}465.12(799.44) \\
17,60,178,528,1847\end{array}$ \\
\hline 0.15 & $\begin{array}{c}392.14(688.25) \\
20,51,130,408,1699\end{array}$ & $\begin{array}{c}396.03(639.04) \\
17,54,153,449,1628\end{array}$ & $\begin{array}{c}425.17(1354.14) \\
17,45,115,357,1711\end{array}$ & $\begin{array}{c}433.35(1472.35) \\
14,44,125,373,1676\end{array}$ & $\begin{array}{c}391.53(765.37) \\
18,45,120,387,1688\end{array}$ & $\begin{array}{c}400.77(737.86) \\
15,48,141,429,1650\end{array}$ \\
\hline 0.20 & $\begin{array}{c}310.62(612.46) \\
18,40,94,281,1396\end{array}$ & $\begin{array}{c}328.86(576.85) \\
15,42,114,345,1409\end{array}$ & $\begin{array}{c}374.96(1220.86) \\
16,38,93,289,1505\end{array}$ & $\begin{array}{c}398.09(1491.81) \\
12,38,104,320,1537\end{array}$ & $\begin{array}{c}330.57(727.18) \\
16,37,88,282,1482\end{array}$ & $\begin{array}{c}343.04(686.23) \\
13,38,105,339,1473\end{array}$ \\
\hline 0.25 & $\begin{array}{c}236.07(500.18) \\
16,34,70,192,1083\end{array}$ & $\begin{array}{c}257.51(516.17) \\
13,33,82,243,1117\end{array}$ & $\begin{array}{c}324.82(1009.33) \\
15,33,75,235,1353\end{array}$ & $\begin{array}{c}327.31(1053.01) \\
12,31,82,260,1284\end{array}$ & $\begin{array}{c}257.97(620.30) \\
14,31,66,197,1159\end{array}$ & $\begin{array}{c}279.22(614.79) \\
12,30,76,245,1245\end{array}$ \\
\hline 0.50 & $\begin{array}{c}50.72(155.31) \\
11,17,25,43,126\end{array}$ & $\begin{array}{c}53.04(129.29) \\
9,15,25,47,161\end{array}$ & $\begin{array}{c}96.56(466.12) \\
10,17,29,58,290\end{array}$ & $\begin{array}{c}107.21(494.73) \\
8,15,29,66,355\end{array}$ & $\begin{array}{c}56.48(209.38) \\
10,16,24,42,147\end{array}$ & $\begin{array}{c}62.42(218.48) \\
7,13,23,45,196\end{array}$ \\
\hline 0.75 & $\begin{array}{c}20.06(40.58) \\
9,12,16,22,39\end{array}$ & $\begin{array}{c}18.70(21.53) \\
7,10,14,21,43\end{array}$ & $\begin{array}{c}29.81(139.13) \\
7,12,17,26,61 \\
\end{array}$ & $\begin{array}{c}29.36(89.69) \\
6,10,15,27,81\end{array}$ & $\begin{array}{c}18.68(49.11) \\
7,11,14,20,39\end{array}$ & $\begin{array}{c}18.14(39.01) \\
6,9,12,19,44 \\
\end{array}$ \\
\hline 1.00 & $\begin{array}{c}13.57(8.86) \\
7,10,12,16,24\end{array}$ & $\begin{array}{c}11.94(6.38) \\
6,8,10,14,23\end{array}$ & $\begin{array}{c}14.26(11.63) \\
6,9,12,16,29 \\
\end{array}$ & $\begin{array}{c}13.17(15.31) \\
5,7,10,15,30\end{array}$ & $\begin{array}{c}11.75(6.62) \\
6,8,10,14,21\end{array}$ & $\begin{array}{c}10.26(6.70) \\
5,7,9,12,21\end{array}$ \\
\hline 1.50 & $\begin{array}{c}9.34(2.41) \\
6,8,9,11,14\end{array}$ & $\begin{array}{c}7.79(2.47) \\
5,6,7,9,13\end{array}$ & $\begin{array}{c}8.01(3.11) \\
4,6,7,9,14\end{array}$ & $\begin{array}{c}6.79(3.21) \\
3,5,6,8,12 \\
\end{array}$ & $\begin{array}{c}7.39(2.15) \\
5,6,7,8,11\end{array}$ & $\begin{array}{c}6.07(2.14) \\
4,5,6,7,10\end{array}$ \\
\hline 2.00 & $\begin{array}{c}7.66(1.48) \\
6,7,7,8,10 \\
\end{array}$ & $\begin{array}{l}6.35(1.53) \\
5,5,6,7,9 \\
\end{array}$ & $\begin{array}{l}5.81(1.74) \\
4,5,6,7,9 \\
\end{array}$ & $\begin{array}{l}4.65(1.60) \\
3,4,4,5,8 \\
\end{array}$ & $\begin{array}{l}5.70(1.27) \\
4,5,5,6,8 \\
\end{array}$ & $\begin{array}{l}4.56(1.21) \\
3,4,4,5,7 \\
\end{array}$ \\
\hline 3.00 & $\begin{array}{l}6.37(0.89) \\
5,6,6,7,8 \\
\end{array}$ & $\begin{array}{l}5.12(0.85) \\
4,5,5,6,7 \\
\end{array}$ & $\begin{array}{l}3.81(0.89) \\
3,3,4,4,5 \\
\end{array}$ & $\begin{array}{l}3.04(0.80) \\
2,3,3,3,4 \\
\end{array}$ & $\begin{array}{l}4.30(0.66) \\
3,4,4,5,5 \\
\end{array}$ & $\begin{array}{l}3.39(0.59) \\
3,3,3,4,4\end{array}$ \\
\hline
\end{tabular}

Table $^{\mathbf{f}}$ 5.Control chart performance comparison under the Symmetric Mixture Normal distribution $\left[0.6 N\left(\mu_{1}=0, \sigma_{1}=0.25\right)+0.4 N\left(\mu_{2}=0, \sigma_{2}=4\right)\right]$ for $m=100$ and $n=5$

\begin{tabular}{|c|c|c|c|c|c|c|}
\hline \multirow[b]{2}{*}{$\begin{array}{l}\text { Control } \\
\text { limits }\end{array}$} & \multicolumn{2}{|c|}{ EWMA-EX } & \multicolumn{2}{|c|}{ EWMA- $\bar{X}$} & \multicolumn{2}{|c|}{ EWMA-Rank } \\
\hline & $\begin{array}{c}1.991 ; 3.058 \\
\text { with } L=1.75\end{array}$ & $\begin{array}{c}1.735 ; 3.314 \\
\text { with } L=2.22\end{array}$ & $\begin{array}{c} \pm 0.448 \\
\text { with } L=2.770\end{array}$ & $\begin{array}{c} \pm 0.656 \\
\text { with } L=2.833\end{array}$ & $234.2 ; 295.8$ & $219.5 ; 310.5$ \\
\hline $\begin{array}{c}\text { Shift } \\
(\gamma)\end{array}$ & 0.05 & 0.10 & 0.05 & 0.10 & 0.05 & 0.10 \\
\hline 0.00 & $\begin{array}{c}506.89(790.60) \\
25,71,198,597,2042 \\
\end{array}$ & $\begin{array}{c}506.84(720.55) \\
21,78,232,628,1942 \\
\end{array}$ & $\begin{array}{c}506.34(1361.96) \\
21,58,154,450,2010 \\
\end{array}$ & $\begin{array}{c}505.01(1561.21) \\
16,55,155,441,1913 \\
\end{array}$ & $\begin{array}{c}487.43(795.70) \\
23,67,187,557,1969 \\
\end{array}$ & $\begin{array}{c}513.18(774.04) \\
19,74,220,619,2005\end{array}$ \\
\hline 0.05 & $\begin{array}{c}313.78(625.87) \\
17,38,91,284,1426\end{array}$ & $\begin{array}{c}356.59(614.11) \\
15,44,122,386,1526\end{array}$ & $\begin{array}{c}505.78(1382.82) \\
20,56,148,441,2014\end{array}$ & $\begin{array}{c}490.08(1397.33) \\
15,53,152,436,1906\end{array}$ & $\begin{array}{c}375.28(711.98) \\
19,44,113, \quad 376,1655\end{array}$ & $\begin{array}{c}393.12(704.22) \\
14,44,131,423,1655\end{array}$ \\
\hline 0.10 & $\begin{array}{c}95.66(289.98) \\
12,21,33,65,310 \\
\end{array}$ & $\begin{array}{c}118.15(299.58) \\
10,19,37,89,471 \\
\end{array}$ & $\begin{array}{c}481.62(1421.92) \\
19,51,133,408,1922 \\
\end{array}$ & $\begin{array}{c}468.30(1421.11) \\
15,49,138,408,1794 \\
\end{array}$ & $\begin{array}{c}177.55(562.09) \\
12,23,43,107,750 \\
\end{array}$ & $\begin{array}{c}180.34(459.67) \\
10,22,47,133,790 \\
\end{array}$ \\
\hline 0.15 & $\begin{array}{c}29.65(56.82) \\
10,14,20,30,68 \\
\end{array}$ & $\begin{array}{c}35.05(80.90) \\
8,13,19,33,96 \\
\end{array}$ & $\begin{array}{c}430.93(1308.40) \\
17,45,116,359,1749 \\
\end{array}$ & $\begin{array}{c}431.68(1323.62) \\
13,42,118,360,1704 \\
\end{array}$ & $\begin{array}{c}53.97(176.72) \\
10,16,24,41,149 \\
\end{array}$ & $\begin{array}{c}63.70(203.99) \\
8,14,23,47,201 \\
\end{array}$ \\
\hline 0.20 & $\begin{array}{c}17.19(10.72) \\
8,11,15,20,33\end{array}$ & $\begin{array}{c}17.20(19.95) \\
7,10,13,19,38\end{array}$ & $\begin{array}{c}391.32(1284.17) \\
16,38,95,300,1586\end{array}$ & $\begin{array}{c}387.35(1260.41) \\
12,35,97,311,1565 \\
\end{array}$ & $\begin{array}{c}24.40(29.31) \\
8,13,17,26,60\end{array}$ & $\begin{array}{c}26.37(65.03) \\
6,10,15,26,70 \\
\end{array}$ \\
\hline 0.25 & $\begin{array}{c}13.20(5.28) \\
7,10,12,15,22\end{array}$ & $\begin{array}{c}12.17(6.74) \\
6,8,11,14,23 \\
\end{array}$ & $\begin{array}{c}336.02(1217.08) \\
14,32,75,234,1369\end{array}$ & $\begin{array}{c}328.51(1110.10) \\
11,30,78,248,1312\end{array}$ & $\begin{array}{c}17.41(55.75) \\
7,10,14,19,34\end{array}$ & $\begin{array}{c}15.81(23.33) \\
5,8,12,18,37\end{array}$ \\
\hline 0.50 & $\begin{array}{c}8.68(1.71) \\
6,7,8,10,12 \\
\end{array}$ & $\begin{array}{c}7.46(1.82) \\
5,6,7,8,11 \\
\end{array}$ & $\begin{array}{c}107.08(736.18) \\
10,17,29,58,299 \\
\end{array}$ & $\begin{array}{c}112.68(531.66) \\
7,15,27,63,365 \\
\end{array}$ & $\begin{array}{c}8.34(2.60) \\
5,7,8,10,13 \\
\end{array}$ & $\begin{array}{c}6.94(2.66) \\
4,5,6,8,12 \\
\end{array}$ \\
\hline 0.75 & $\begin{array}{l}8.13(1.47) \\
6,7,8,9,11 \\
\end{array}$ & $\begin{array}{c}6.91(1.54) \\
5,6,7,8,10\end{array}$ & $\begin{array}{c}28.56(129.92) \\
7,12,17,26,63\end{array}$ & $\begin{array}{l}28.98(136.86) \\
5,9,15,25,73\end{array}$ & $\begin{array}{l}6.91(1.87) \\
5,6,7,8,10\end{array}$ & $\begin{array}{l}5.62(1.79) \\
3,4,5,6,9\end{array}$ \\
\hline 1.00 & $\begin{array}{c}7.83(1.35) \\
6,7,8,9,10\end{array}$ & $\begin{array}{l}6.62(1.41) \\
5,6,6,7,9\end{array}$ & $\begin{array}{c}14.54(54.85) \\
6,9,12,16,29\end{array}$ & $\begin{array}{c}13.03(25.01) \\
4,7,10,15,30\end{array}$ & $\begin{array}{l}6.32(1.49) \\
4,5,6,7,9\end{array}$ & $\begin{array}{l}5.10(1.48) \\
3,4,5,6,8\end{array}$ \\
\hline 1.50 & $\begin{array}{l}7.31(1.13) \\
6,7,7,8,9 \\
\end{array}$ & $\begin{array}{l}6.14(1.20) \\
5,5,6,7,8 \\
\end{array}$ & $\begin{array}{c}8.08(3.07) \\
4,6,7,9,14 \\
\end{array}$ & $\begin{array}{c}6.62(3.08) \\
3,5,6,8,12 \\
\end{array}$ & $\begin{array}{l}5.52(1.17) \\
4,5,5,6,8 \\
\end{array}$ & $\begin{array}{l}4.41(1.12) \\
3,4,4,5,6 \\
\end{array}$ \\
\hline 2.00 & $\begin{array}{l}6.93(0.99) \\
6,6,7,7,9\end{array}$ & $\begin{array}{l}5.75(1.04) \\
4,5,6,6,8\end{array}$ & $\begin{array}{l}5.79(1.72) \\
4,5,6,7,9\end{array}$ & $\begin{array}{l}4.62(1.60) \\
3,4,4,5,8 \\
\end{array}$ & $\begin{array}{l}4.95(0.95) \\
4,4,5,5,7\end{array}$ & $\begin{array}{l}3.92(0.90) \\
3,3,4,4,6\end{array}$ \\
\hline 3.00 & $\begin{array}{l}6.34(0.79) \\
5,6,6,7,8\end{array}$ & $\begin{array}{l}5.18(0.80) \\
4,5,5,6,7\end{array}$ & $\begin{array}{l}3.81(0.87) \\
3,3,4,4,5\end{array}$ & $\begin{array}{l}2.99(0.79) \\
2,2,3,3,4\end{array}$ & $\begin{array}{l}4.20(0.67) \\
3,4,4,5,5\end{array}$ & $\begin{array}{l}3.35(0.56) \\
3,3,3,4,4\end{array}$ \\
\hline
\end{tabular}

\footnotetext{
${ }^{\mathrm{e}}$ Note that the first row of each cell shows the $A R L$ followed by the corresponding $S D R L$ in parentheses, whereas the second row shows the values of the $5^{\text {th }}, 25^{\text {th }}, 50^{\text {th }}, 75^{\text {th }}$ and $95^{\text {th }}$ percentiles (in this order).

${ }^{\mathrm{f}}$ Note that the first row of each cell shows the $A R L$ followed by the corresponding $S D R L$ in parentheses, whereas the second row shows the values of the $5^{\text {th }}, 25^{\text {th }}, 50^{\text {th }}, 75^{\text {th }}$ and $95^{\text {th }}$ percentiles (in this order).
} 
Table $^{\mathrm{g}}$ 6.Control chart performance comparison under the Asymmetric Mixture Normal distribution $\left[0.6 N\left(\mu_{1}=0.25, \sigma_{1}=0.25\right)+0.4 N\left(\mu_{2}=0, \sigma_{2}=4\right)\right]$ for $m=100$ and $n=5$

\begin{tabular}{|c|c|c|c|c|c|c|}
\hline & \multicolumn{2}{|c|}{ EWMA-EX } & \multicolumn{2}{|c|}{ EWMA- $\bar{X}$} & \multicolumn{2}{|c|}{ EWMA-Rank } \\
\hline $\begin{array}{l}\text { Control } \\
\text { limits }\end{array}$ & $\begin{array}{c}1.991 ; 3.058 \\
\text { with } L=1.75 \\
\end{array}$ & $\begin{array}{c}1.735 ; 3.314 \\
\text { with } L=2.22 \\
\end{array}$ & $\begin{array}{c} \pm 0.447 \\
\text { with } L=2.762\end{array}$ & $\begin{array}{c} \pm 0.657 \\
\text { with } L=2.835\end{array}$ & $234.2 ; 295.8$ & $219.5 ; 310.5$ \\
\hline $\begin{array}{c}\text { Shift } \\
(\gamma)\end{array}$ & 0.05 & 0.10 & 0.05 & 0.10 & 0.05 & 0.10 \\
\hline 0.00 & $\begin{array}{c}511.42(803.11) \\
25,71,199,593,2085 \\
\end{array}$ & $\begin{array}{c}507.79(723.57) \\
21,80,234,628,1927 \\
\end{array}$ & $\begin{array}{c}509.61(1426.34) \\
20,57,153,447,1991 \\
\end{array}$ & $\begin{array}{c}501.96(1475.70) \\
16,55,156,448,1937 \\
\end{array}$ & $\begin{array}{c}486.57(788.21) \\
23,67,187,550,1978 \\
\end{array}$ & $\begin{array}{c}516.08(800.09) \\
20,73,217,618,2000 \\
\end{array}$ \\
\hline 0.05 & $\begin{array}{c}335.59(645.52) \\
18,41,99,318,1503 \\
\end{array}$ & $\begin{array}{c}355.83(609.91) \\
15,43,122,383,1525 \\
\end{array}$ & $\begin{array}{c}488.42(1278.59) \\
20,55,146,437,1941 \\
\end{array}$ & $\begin{array}{c}489.37(1416.80) \\
16,54,151,438,1896 \\
\end{array}$ & $\begin{array}{c}366.78(691.13) \\
18,42,109,360,1643\end{array}$ & $\begin{array}{c}388.37(691.33) \\
14,44,129,417,1664 \\
\end{array}$ \\
\hline 0.10 & $\begin{array}{c}105.68(293.99) \\
13,22,36,74,388\end{array}$ & $\begin{array}{c}118.97(303.57) \\
10,20,38,89,471\end{array}$ & $\begin{array}{c}470.02(1313.01) \\
19,51,134,403,1868\end{array}$ & $\begin{array}{c}472.32(1423.44) \\
15,48,137,408,1834\end{array}$ & $\begin{array}{c}161.21(430.82) \\
12,23,43,105,699\end{array}$ & $\begin{array}{c}180.74(448.38) \\
10,21,47,132,810\end{array}$ \\
\hline 0.15 & $\begin{array}{c}32.08(72.77) \\
10,15,21,31,74\end{array}$ & $\begin{array}{c}34.15(79.42) \\
8,13,19,33,92 \\
\end{array}$ & $\begin{array}{c}428.95(1388.73) \\
17,44,114,352,1719 \\
\end{array}$ & $\begin{array}{c}428.19(1310.61) \\
14,42,120,366,1687\end{array}$ & $\begin{array}{c}56.69(197.99) \\
10,16,25,43,154 \\
\end{array}$ & $\begin{array}{c}64.82(207.00) \\
7,14,23,47,204 \\
\end{array}$ \\
\hline 0.20 & $\begin{array}{c}17.92(20.55) \\
8,12,15,20,35\end{array}$ & $\begin{array}{c}17.21(17.97) \\
7,10,13,20,39\end{array}$ & $\begin{array}{c}379.56(1170.30) \\
16,38,93,291,1567\end{array}$ & $\begin{array}{c}387.71(1251.30) \\
12,35,98,313,1557\end{array}$ & $\begin{array}{c}25.18(51.41) \\
8,12,17,26,58\end{array}$ & $\begin{array}{c}26.20(58.17) \\
6,10,15,26,70\end{array}$ \\
\hline 0.25 & $\begin{array}{c}13.59(8.34) \\
8,10,12,16,23\end{array}$ & $\begin{array}{c}12.15(6.36) \\
6,8,11,14,23\end{array}$ & $\begin{array}{c}325.57(1104.52) \\
14,32,74,232,1335\end{array}$ & $\begin{array}{c}333.13(1214.22) \\
11,30,78,249,1336\end{array}$ & $\begin{array}{c}16.52(13.34) \\
7,10,14,19,34\end{array}$ & $\begin{array}{c}15.71(18.43) \\
5,8,12,18,37\end{array}$ \\
\hline 0.50 & $\begin{array}{c}8.90(1.74) \\
7,8,9,10,12\end{array}$ & $\begin{array}{c}7.45(1.83) \\
5,6,7,8,11\end{array}$ & $\begin{array}{c}97.51(456.45) \\
10,17,28,56,294\end{array}$ & $\begin{array}{c}110.22(548.28) \\
7,14,27,63,364\end{array}$ & $\begin{array}{c}8.36(2.62) \\
5,7,8,10,13\end{array}$ & $\begin{array}{c}6.93(2.67) \\
4,5,6,8,12\end{array}$ \\
\hline 0.75 & $\begin{array}{c}8.32(1.47) \\
6,7,8,9,11\end{array}$ & $\begin{array}{c}6.91(1.53) \\
5,6,7,8,10\end{array}$ & $\begin{array}{c}28.22(150.07) \\
7,12,17,26,64\end{array}$ & $\begin{array}{l}29.71(151.64) \\
5,9,14,25,73\end{array}$ & $\begin{array}{c}6.93(1.81) \\
5,6,7,8,10\end{array}$ & $\begin{array}{l}5.61(1.78) \\
3,4,5,6,9\end{array}$ \\
\hline 1.00 & $\begin{array}{c}8.00(1.34) \\
6,7,8,9,10\end{array}$ & $\begin{array}{l}6.62(1.41) \\
5,6,6,7,9\end{array}$ & $\begin{array}{c}14.17(12.71) \\
6,9,12,16,29\end{array}$ & $\begin{array}{c}13.03(22.89) \\
4,7,10,15,30\end{array}$ & $\begin{array}{l}6.32(1.54) \\
4,5,6,7,9\end{array}$ & $\begin{array}{l}5.10(1.48) \\
3,4,5,6,8\end{array}$ \\
\hline 1.50 & $\begin{array}{c}7.49(1.17) \\
6,7,7,8,10 \\
\end{array}$ & $\begin{array}{l}6.13(1.20) \\
5,5,6,7,8 \\
\end{array}$ & $\begin{array}{c}8.04(3.09) \\
4,6,7,9,14 \\
\end{array}$ & $\begin{array}{c}6.64(3.08) \\
3,5,6,8,12 \\
\end{array}$ & $\begin{array}{l}5.52(1.19) \\
4,5,5,6,8 \\
\end{array}$ & $\begin{array}{l}4.41(1.13) \\
3,4,4,5,6 \\
\end{array}$ \\
\hline 2.00 & $\begin{array}{l}7.08(1.03) \\
6,6,7,8,9\end{array}$ & $\begin{array}{l}5.75(1.04) \\
4,5,6,6,8\end{array}$ & $\begin{array}{l}5.76(1.72) \\
4,5,5,7,9\end{array}$ & $\begin{array}{l}4.61(1.60) \\
3,4,4,5,8\end{array}$ & $\begin{array}{l}4.96(0.95) \\
4,4,5,5,7\end{array}$ & $\begin{array}{l}3.93(0.89) \\
3,3,4,4,6\end{array}$ \\
\hline 3.00 & $\begin{array}{l}6.42(0.84) \\
5,6,6,7,8\end{array}$ & $\begin{array}{l}5.18(0.80) \\
4,5,5,6,7\end{array}$ & $\begin{array}{l}3.79(0.87) \\
3,3,4,4,5\end{array}$ & $\begin{array}{l}2.98(0.79) \\
2,2,3,3,4\end{array}$ & $\begin{array}{l}4.20(0.67) \\
3,4,4,5,5\end{array}$ & $\begin{array}{l}3.34(0.56) \\
3,3,3,4,4\end{array}$ \\
\hline
\end{tabular}

Table $^{\mathrm{h}}$ 7.Control chart performance comparison under the Asymmetric Mixture Normal distribution $\left[0.6 N\left(\mu_{1}=-0.25, \sigma_{1}=0.25\right)+0.4 N\left(\mu_{2}=0, \sigma_{2}=4\right)\right]$ for $m=100$ and $n=5$

\begin{tabular}{|c|c|c|c|c|c|c|}
\hline \multirow[b]{2}{*}{$\begin{array}{l}\text { Control } \\
\text { limits }\end{array}$} & \multicolumn{2}{|c|}{ EWMA-EX } & \multicolumn{2}{|c|}{ EWMA- $\bar{X}$} & \multicolumn{2}{|c|}{ EWMA-Rank } \\
\hline & $\begin{array}{c}1.991 ; 3.058 \\
\text { with } L=1.75\end{array}$ & $\begin{array}{c}1.735 ; 3.314 \\
\text { with } L=2.22\end{array}$ & $\begin{array}{c} \pm 0.446 \\
\text { with } L=2.760\end{array}$ & $\begin{array}{c} \pm 0.833 \\
\text { with } L=2.833\end{array}$ & $234.2 ; 295.8$ & $219.5 ; 310.5$ \\
\hline $\begin{array}{c}\text { Shift } \\
(\gamma)\end{array}$ & 0.05 & 0.10 & 0.05 & 0.10 & 0.05 & 0.10 \\
\hline 0.00 & $\begin{array}{c}506.54(789.23) \\
25,71,198,590,2071\end{array}$ & $\begin{array}{c}509.83(732.22) \\
21,79,231,634,1964\end{array}$ & $\begin{array}{c}504.13(1373.32) \\
21,57,150,451,1999\end{array}$ & $\begin{array}{c}502.99(1490.60) \\
16,55,156,449,1903\end{array}$ & $\begin{array}{c}490.32(782.31) \\
23,68,191,558,2006\end{array}$ & $\begin{array}{c}507.55(781.94) \\
20,73,218,612,1972\end{array}$ \\
\hline 0.05 & $\begin{array}{c}341.38(644.00) \\
18,42,102,325,1541\end{array}$ & $\begin{array}{c}356.11(613.31) \\
15,43,122,384,1516\end{array}$ & $\begin{array}{c}495.23(1465.10) \\
20,55,143,429,1938\end{array}$ & $\begin{array}{c}499.77(1545.90) \\
15,52,151,436,1930\end{array}$ & $\begin{array}{c}369.61(701.62) \\
18,43,110,361,1639\end{array}$ & $\begin{array}{c}382.40(673.41) \\
14,44,128,411,1630\end{array}$ \\
\hline 0.10 & $\begin{array}{c}105.59(297.14) \\
13,22,36,73,380\end{array}$ & $\begin{array}{c}117.28(300.19) \\
10,19,37,88,464\end{array}$ & $\begin{array}{c}468.68(1325.81) \\
19,50,132,398,1878\end{array}$ & $\begin{array}{c}474.33(1384.43) \\
14,48,137,404,1837\end{array}$ & $\begin{array}{c}161.74(433.80) \\
13,23,43,104,699\end{array}$ & $\begin{array}{c}180.95(446.87) \\
10,22,46,130,825\end{array}$ \\
\hline 0.15 & $\begin{array}{c}32.27(77.15) \\
10,15,21,31,74\end{array}$ & $\begin{array}{c}34.46(87.92) \\
8,13,19,33,94\end{array}$ & $\begin{array}{c}420.51(1169.44) \\
17,44,113,346,1721\end{array}$ & $\begin{array}{c}427.88(1294.19) \\
13,42,120,365,1668\end{array}$ & $\begin{array}{c}56.96(203.68) \\
10,16,24,43,158\end{array}$ & $\begin{array}{c}64.42(203.50) \\
7,14,24,48,205\end{array}$ \\
\hline 0.20 & $\begin{array}{c}17.84(11.87) \\
9,12,15,20,35\end{array}$ & $\begin{array}{l}17.05(17.00) \\
10,13,19,38\end{array}$ & $\begin{array}{c}379.08(1251.18) \\
16,38,92,294,1540\end{array}$ & $\begin{array}{c}386.42(1291.41) \\
12,35,98,302,1518\end{array}$ & $\begin{array}{c}24.99(52.06) \\
8,12,17,26,58\end{array}$ & $\begin{array}{c}26.09(62.84) \\
6,10,16,26,68\end{array}$ \\
\hline 0.25 & $\begin{array}{c}13.52(5.33) \\
8,10,12,16,23\end{array}$ & $\begin{array}{c}12.17(6.46) \\
6,8,11,14,23\end{array}$ & $\begin{array}{c}320.87(1068.66) \\
14,32,72,225,1314\end{array}$ & $\begin{array}{c}331.96(1083.49) \\
11,30,78,249,1314\end{array}$ & $\begin{array}{c}16.60(14.00) \\
7,10,14,19,34\end{array}$ & $\begin{array}{c}15.69(22.94) \\
5,8,12,17,36\end{array}$ \\
\hline 0.50 & $\begin{array}{c}8.90(1.73) \\
7,8,9,10,12\end{array}$ & $\begin{array}{c}7.47(1.84) \\
5,6,7,8,11\end{array}$ & $\begin{array}{c}103.26(504.63) \\
10,17,29,58,312\end{array}$ & $\begin{array}{c}113.37(703.62) \\
7,14,27,63,364\end{array}$ & $\begin{array}{c}8.35(2.60) \\
5,7,8,10,13\end{array}$ & $\begin{array}{c}6.92(2.66) \\
4,5,6,8,12\end{array}$ \\
\hline 0.75 & $\begin{array}{l}8.31(1.46) \\
6,7,8,9,11\end{array}$ & $\begin{array}{c}6.91(1.54) \\
5,6,7,8,10\end{array}$ & $\begin{array}{c}27.65(100.01) \\
7,12,17,26,63\end{array}$ & $\begin{array}{l}30.19(199.36) \\
5,9,15,25,74\end{array}$ & $\begin{array}{c}6.92(1.82) \\
5,6,7,8,10\end{array}$ & $\begin{array}{l}5.63(1.78) \\
3,4,5,6,9\end{array}$ \\
\hline 1.00 & $\begin{array}{l}8.00(1.35) \\
6,7,8,9,10\end{array}$ & $\begin{array}{l}6.62(1.39) \\
5,6,6,7,9\end{array}$ & $\begin{array}{c}14.25(22.46) \\
6,9,12,16,29\end{array}$ & $\begin{array}{c}13.17(37.73) \\
4,7,10,15,30\end{array}$ & $\begin{array}{l}6.33(1.54) \\
4,5,6,7,9\end{array}$ & $\begin{array}{l}5.11(1.48) \\
3,4,5,6,8\end{array}$ \\
\hline 1.50 & $\begin{array}{c}7.49(1.17) \\
6,7,7,8,10\end{array}$ & $\begin{array}{l}6.14(1.20) \\
5,5,6,7,8\end{array}$ & $\begin{array}{c}8.03(3.07) \\
4,6,7,9,14\end{array}$ & $\begin{array}{c}6.64(3.19) \\
3,5,6,8,12\end{array}$ & $\begin{array}{l}5.53(1.19) \\
4,5,5,6,8\end{array}$ & $\begin{array}{l}4.41(1.12) \\
3,4,4,5,6\end{array}$ \\
\hline 2.00 & $\begin{array}{l}7.07(1.03) \\
6,6,7,8,9\end{array}$ & $\begin{array}{l}5.75(1.03) \\
4,5,6,6,8\end{array}$ & $\begin{array}{l}5.77(1.72) \\
4,5,6,7,9\end{array}$ & $\begin{array}{l}4.61(1.61) \\
3,4,4,5,8\end{array}$ & $\begin{array}{l}4.96(0.95) \\
4,4,5,5,7\end{array}$ & $\begin{array}{l}3.93(0.90) \\
3,3,4,4,6\end{array}$ \\
\hline 3.00 & $\begin{array}{l}6.42(0.84) \\
5,6,6,7,8\end{array}$ & $\begin{array}{l}5.18(0.80) \\
4,5,5,6,7\end{array}$ & $\begin{array}{l}3.79(0.87) \\
3,3,4,4,5\end{array}$ & $\begin{array}{l}2.97(0.78) \\
2,2,3,3,4\end{array}$ & $\begin{array}{l}4.20(0.67) \\
3,4,4,5,5\end{array}$ & $\begin{array}{l}3.35(0.57) \\
3,3,3,4,4\end{array}$ \\
\hline
\end{tabular}

\footnotetext{
${ }^{\mathrm{g}}$ Note that the first row of each cell shows the $A R L$ followed by the corresponding $S D R L$ in parentheses, whereas the second row shows the values of the $5^{\text {th }}, 25^{\text {th }}, 50^{\text {th }}, 75^{\text {th }}$ and $95^{\text {th }}$ percentiles (in this order).

${ }^{\mathrm{h}}$ Note that the first row of each cell shows the $A R L$ followed by the corresponding $S D R L$ in parentheses, whereas the second row shows the values of the $5^{\text {th }}, 25^{\text {th }}, 50^{\text {th }}, 75^{\text {th }}$ and $95^{\text {th }}$ percentiles (in this order).
} 
Table ${ }^{\mathrm{i}}$ 8. Control chart performance comparison under the Log-Logistic distribution $[\alpha=1, \beta=2.5]$ for $m=100$ and $n=5$

\begin{tabular}{|c|c|c|c|c|c|c|}
\hline \multirow{3}{*}{$\begin{array}{c}\text { Control } \\
\text { limits } \\
\text { Shift } \\
(\gamma) \\
\end{array}$} & \multicolumn{2}{|c|}{ EWMA-EX } & \multicolumn{2}{|c|}{ EWMA- $\bar{X}$} & \multicolumn{2}{|c|}{ EWMA-Rank } \\
\hline & $\begin{array}{c}1.991 ; 3.058 \\
\text { with } L=1.75\end{array}$ & \multirow{2}{*}{$\begin{array}{c}1.735 ; 3.314 \\
\text { with } L=2.22 \\
0.10\end{array}$} & \multirow[t]{2}{*}{$* * *$} & \multirow[t]{2}{*}{$* * *$} & \multirow{2}{*}{$\begin{array}{c}234.2 ; 295.8 \\
0.05\end{array}$} & \multirow{2}{*}{$\begin{array}{c}219.5 ; 310.5 \\
0.10\end{array}$} \\
\hline & 0.05 & & & & & \\
\hline 0.00 & $\begin{array}{c}503.26(788.70) \\
25,71,196,585,2045 \\
\end{array}$ & $\begin{array}{c}506.94(724.35) \\
21,78,229,628,1939 \\
\end{array}$ & & & $\begin{array}{c}501.83(860.25) \\
23,68,191,553,2038 \\
\end{array}$ & $\begin{array}{c}507.54(830.23) \\
20,73,215,590,1948\end{array}$ \\
\hline 0.05 & $\begin{array}{c}473.42(766.54) \\
22,63,174,537,1978 \\
\end{array}$ & $\begin{array}{c}479.55(711.66) \\
19,68,204,584,1884\end{array}$ & & & $\begin{array}{c}494.88(921.98) \\
21,57,156,513,2120\end{array}$ & $\begin{array}{c}530.73(994.48) \\
17,61,188,572,2157\end{array}$ \\
\hline 0.10 & $\begin{array}{c}380.59(686.69) \\
18,45,117,386,1683\end{array}$ & $\begin{array}{c}389.53(640.46) \\
15,47,141,440,1622\end{array}$ & & & $\begin{array}{c}406.28(1046.49) \\
16,37,89,318,1874 \\
\end{array}$ & $\begin{array}{c}442.28(1009.91) \\
14,38,111,393,1974\end{array}$ \\
\hline 0.15 & $\begin{array}{c}274.79(584.13) \\
15,32,70,227,1283 \\
\end{array}$ & $\begin{array}{c}291.19(557.32) \\
12,31,84,284,1307 \\
\end{array}$ & & & $\begin{array}{c}261.16(847.56) \\
13,25,49,140,1188 \\
\end{array}$ & $\begin{array}{c}313.50(940.90) \\
11,24,57,197,1434 \\
\end{array}$ \\
\hline 0.20 & $\begin{array}{c}182.17(448.29) \\
12,23,44,121,855 \\
\end{array}$ & $\begin{array}{c}196.86(440.25) \\
10,22,49,154,935 \\
\end{array}$ & & & $\begin{array}{c}156.65(724.44) \\
11,19,32,69,515 \\
\end{array}$ & $\begin{array}{c}187.53(809.01) \\
9,17,34,92,715 \\
\end{array}$ \\
\hline 0.25 & $\begin{array}{c}108.91(326.17) \\
11,18,31,66,424 \\
\end{array}$ & $\begin{array}{c}117.08(315.08) \\
8,16,31,78,500 \\
\end{array}$ & & & $\begin{array}{c}79.30(511.05) \\
10,15,23,41,174\end{array}$ & $\begin{array}{c}105.04(718.96) \\
8,13,23,49,277\end{array}$ \\
\hline 0.50 & $\begin{array}{c}14.31(22.17) \\
7,9,11,15,28\end{array}$ & $\begin{array}{l}13.20(26.20) \\
5,7,9,14,29 \\
\end{array}$ & & & $\begin{array}{c}11.46(7.31) \\
6,8,10,13,21 \\
\end{array}$ & $\begin{array}{c}10.31(9.16) \\
5,7,9,12,21 \\
\end{array}$ \\
\hline 0.75 & $\begin{array}{c}7.76(2.60) \\
5,6,7,8,12 \\
\end{array}$ & $\begin{array}{c}6.37(2.30) \\
4,5,6,7,10 \\
\end{array}$ & & & $\begin{array}{c}7.19(1.85) \\
5,6,7,8,11 \\
\end{array}$ & $\begin{array}{l}5.87(1.84) \\
4,5,5,7,9 \\
\end{array}$ \\
\hline 1.00 & $\begin{array}{l}5.91(0.93) \\
5,5,6,6,8\end{array}$ & $\begin{array}{l}4.76(0.85) \\
4,4,5,5,6\end{array}$ & & & $\begin{array}{l}5.60(1.01) \\
4,5,5,6,7\end{array}$ & $\begin{array}{l}4.46(0.92) \\
3,4,4,5,6\end{array}$ \\
\hline 1.50 & $\begin{array}{l}5.01(0.08) \\
5,5,5,5,5 \\
\end{array}$ & $\begin{array}{l}4.01(0.07) \\
4,4,4,4,4 \\
\end{array}$ & & & $\begin{array}{l}4.30(0.50) \\
4,4,4,5,5 \\
\end{array}$ & $\begin{array}{l}3.35(0.50) \\
3,3,3,4,4\end{array}$ \\
\hline 2.00 & $\begin{array}{l}5.00(0.00) \\
5,5,5,5,5 \\
\end{array}$ & $\begin{array}{l}4.00(0.00) \\
4,4,4,4,4 \\
\end{array}$ & & & $\begin{array}{l}3.91(0.34) \\
3,4,4,4,4 \\
\end{array}$ & $\begin{array}{l}3.03(0.16) \\
3,3,3,3,3 \\
\end{array}$ \\
\hline 3.00 & $\begin{array}{l}5.00(0.00) \\
5,5,5,5,5\end{array}$ & $\begin{array}{l}4.00(0.00) \\
4,4,4,4,4\end{array}$ & & & $\begin{array}{l}3.25(0.43) \\
3,3,3,3,4\end{array}$ & $\begin{array}{l}2.96(0.19) \\
3,3,3,3,3\end{array}$ \\
\hline
\end{tabular}

*** The run-length characteristics can't be computed for the EWMA- $\bar{X}$ chart based on Normal Theory, since the run-length characteristics don't converge

Table $^{\mathrm{j}}$ 9.Effect of reference sample size on the EWMA-EX chart under the $N(0,1)$ distribution for $\lambda=0.05$ and $n=5$

\begin{tabular}{|c|c|c|c|c|c|c|}
\hline \multirow[b]{2}{*}{$m$} & \multicolumn{6}{|c|}{ EWMA-EX } \\
\hline & 20 & 50 & 100 & 500 & 1000 & $\begin{array}{l}\text { Parameters known } \\
\text { or specified }\end{array}$ \\
\hline $\begin{array}{l}\text { Control } \\
\text { Limits }\end{array}$ & $\begin{array}{c}2.039 ; 3.120 \\
\text { with } L=1.036\end{array}$ & $\begin{array}{c}1.996 ; 3.102 \\
\text { with } L=1.42\end{array}$ & $\begin{array}{c}1.991 ; 3.058 \\
\text { with } L=1.75\end{array}$ & $\begin{array}{c}\text { 2.010;3.000 } \\
\text { with } L=2.35\end{array}$ & $\begin{array}{c}2.019 ; 2.986 \\
\text { with } L=2.47\end{array}$ & $\begin{array}{l}\text {-0.931, } 0.931 \\
\text { with } L=2.60\end{array}$ \\
\hline $\begin{array}{l}\text { Shift }(\gamma) \\
0.00\end{array}$ & $\begin{array}{c}500.95(1210.72) \\
13,27,72,345,2574\end{array}$ & $\begin{array}{c}504.69(953.55) \\
19,49,143,492,2277\end{array}$ & $\begin{array}{c}508.45(795.41) \\
24,72,200,590,2106\end{array}$ & $\begin{array}{c}498.31(562.59) \\
36,123,303,672,1616\end{array}$ & $\begin{array}{c}500.58(526.46) \\
40,146,335,672,1554\end{array}$ & $\begin{array}{c}500.94(482.31) \\
39,156,352,689,1467\end{array}$ \\
\hline 0.25 & $\begin{array}{c}488.98(1220.19) \\
13,29,75,327,2516\end{array}$ & $\begin{array}{c}458.66(886.23) \\
17,42,121,444,2127\end{array}$ & $\begin{array}{c}398.98(687.24) \\
20,49,130,417,1738\end{array}$ & $\begin{array}{c}222.03(326.81) \\
21,53,111,246,820\end{array}$ & $\begin{array}{c}172.02(213.16) \\
21,51,102,207,557\end{array}$ & $\begin{array}{c}118.99(101.86) \\
20,47,89,158,322\end{array}$ \\
\hline 0.50 & $\begin{array}{c}430.41(1139.25) \\
12,24,57,252,2266\end{array}$ & $\begin{array}{c}300.54(743.68) \\
13,26,56,198,1545\end{array}$ & $\begin{array}{c}185.97(456.32) \\
14,26,49,129,860\end{array}$ & $\begin{array}{c}57.62(67.32) \\
13,25,39,68,156\end{array}$ & $\begin{array}{c}48.23(38.59) \\
13,23,37,60,120\end{array}$ & $\begin{array}{c}40.57(26.43) \\
12,22,34,52,92\end{array}$ \\
\hline 0.75 & $\begin{array}{c}305.57(938.98) \\
10,18,36,127,1631\end{array}$ & $\begin{array}{c}148.49(524.62) \\
11,18,30,70,596\end{array}$ & $\begin{array}{c}62.22(189.51) \\
10,17,27,48,176\end{array}$ & $\begin{array}{c}27.17(17.90) \\
10,16,23,33,59\end{array}$ & $\begin{array}{c}25.07(14.28) \\
10,15,22,31,52\end{array}$ & $\begin{array}{c}22.71(11.52) \\
9,15,20,28,45\end{array}$ \\
\hline 1.00 & $\begin{array}{c}223.61(840.20) \\
9,14,24,65,1067\end{array}$ & $\begin{array}{c}63.25(271.63) \\
9,14,20,34,165\end{array}$ & $\begin{array}{c}24.76(34.77) \\
9,13,18,26,59\end{array}$ & $\begin{array}{c}17.68(8.43) \\
8,12,16,21,33\end{array}$ & $\begin{array}{c}16.73(7.88) \\
8,12,15,20,31\end{array}$ & $\begin{array}{c}15.62(6.51) \\
8,11,14,19,28\end{array}$ \\
\hline 1.50 & $\begin{array}{c}67.81(440.12) \\
7,10,14,22,113\end{array}$ & $\begin{array}{c}16.48(56.58) \\
7,10,12,17,32\end{array}$ & $\begin{array}{c}12.73(6.13) \\
7,9,11,15,23\end{array}$ & $\begin{array}{c}10.84(3.49) \\
7,8,10,13,17\end{array}$ & $\begin{array}{c}10.38(3.27) \\
6,8,10,12,17\end{array}$ & $\begin{array}{c}9.98(3.05) \\
6,8,9,12,16\end{array}$ \\
\hline 2.00 & $\begin{array}{c}16.46(79.83) \\
6,8,10,14,28\end{array}$ & $\begin{array}{c}10.05(4.10) \\
6,8,9,11,17\end{array}$ & $\begin{array}{c}9.20(2.64) \\
6,7,9,10,14\end{array}$ & $\begin{array}{c}8.16(1.99) \\
6,7,8,9,12\end{array}$ & $\begin{array}{l}7.87(1.89) \\
6,6,7,9,11\end{array}$ & $\begin{array}{c}7.50(1.83) \\
5,6,7,9,11\end{array}$ \\
\hline 3.00 & $\begin{array}{c}7.83(2.17) \\
6,6,7,9,12\end{array}$ & $\begin{array}{l}6.84(1.34) \\
5,6,7,7,9\end{array}$ & $\begin{array}{l}6.66(1.08) \\
5,6,7,7,9\end{array}$ & $\begin{array}{l}6.03(0.95) \\
5,5,6,7,8\end{array}$ & $\begin{array}{l}5.90(0.83) \\
5,5,6,6,7\end{array}$ & $\begin{array}{l}5.55(0.81) \\
5,5,5,6,7\end{array}$ \\
\hline
\end{tabular}

\footnotetext{
${ }^{\mathrm{i}}$ Note that the first row of each cell shows the $A R L$ followed by the corresponding $S D R L$ in parentheses, whereas the second row shows the values of the $5^{\text {th }}, 25^{\text {th }}, 50^{\text {th }}, 75^{\text {th }}$ and $95^{\text {th }}$ percentiles (in this order).

${ }^{\mathrm{j}}$ Note that the first row of each cell shows the $A R L$ followed by the corresponding $S D R L$ in parentheses, whereas the second row shows the values of the $5^{\text {th }}, 25^{\text {th }}, 50^{\text {th }}, 75^{\text {th }}$ and $95^{\text {th }}$ percentiles (in this order).
} 


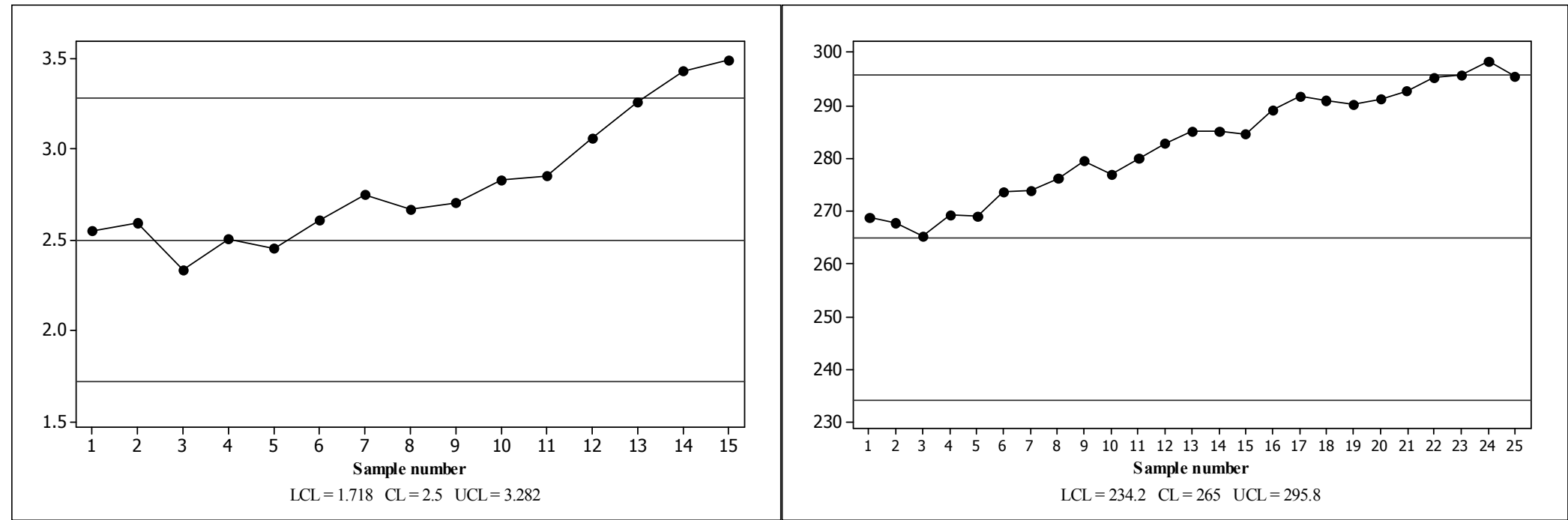

Figure 1. The EWMA-EX control chart for Example 1.Figure 2c. The EWMA-Rank control chart for Example 2.
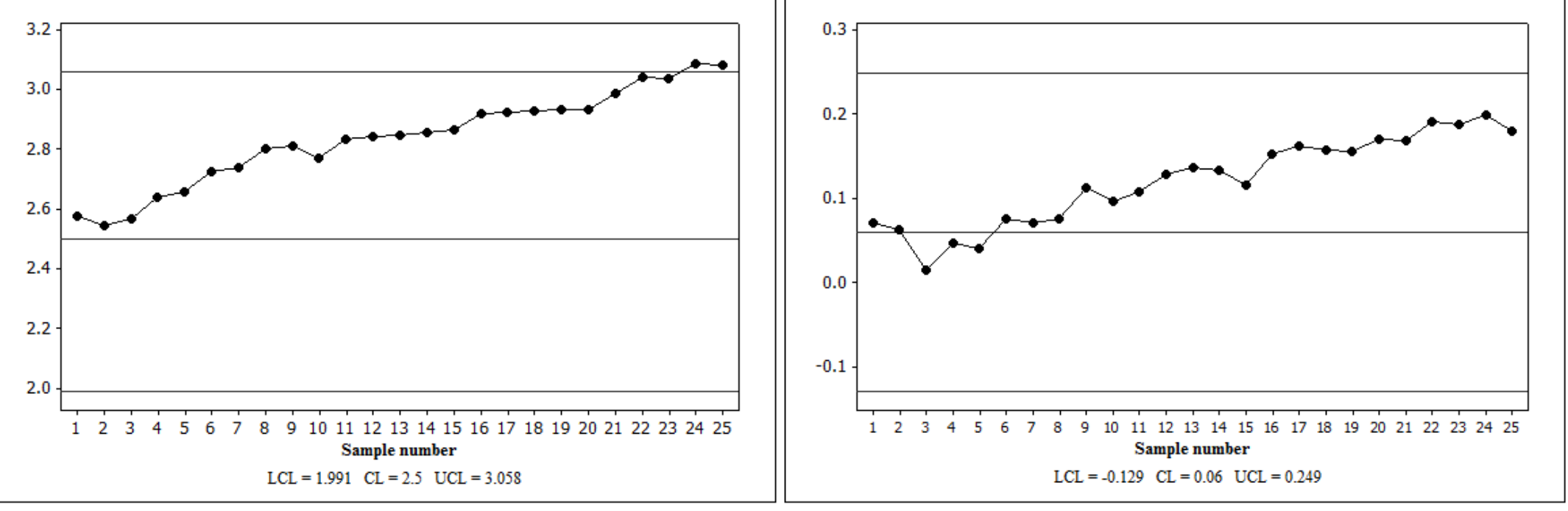

Figure 2a. The EWMA-EX control chart for Example 2.

Figure 2b. The EWMA- $\bar{X}$ control chart for Example 2 . 


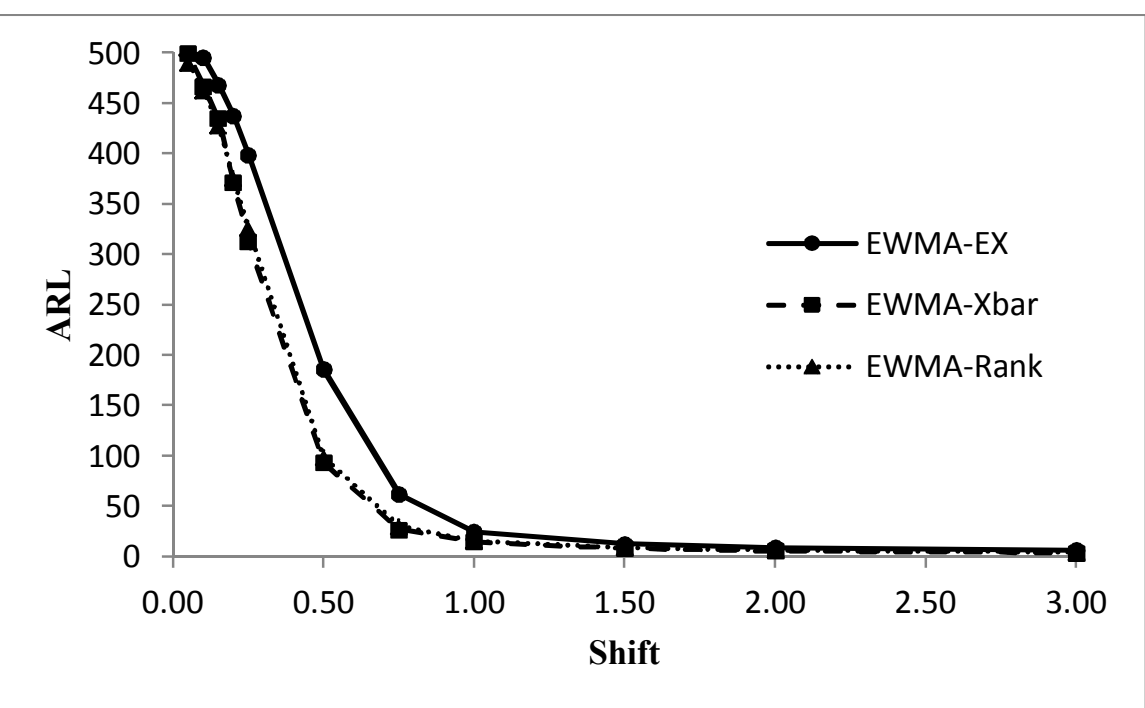

Figure 3a. $A R L$ performance comparison of the competing charts under the $N(0,1)$ distribution for $m=100$ and $n=5$ and $\lambda=0.05$.

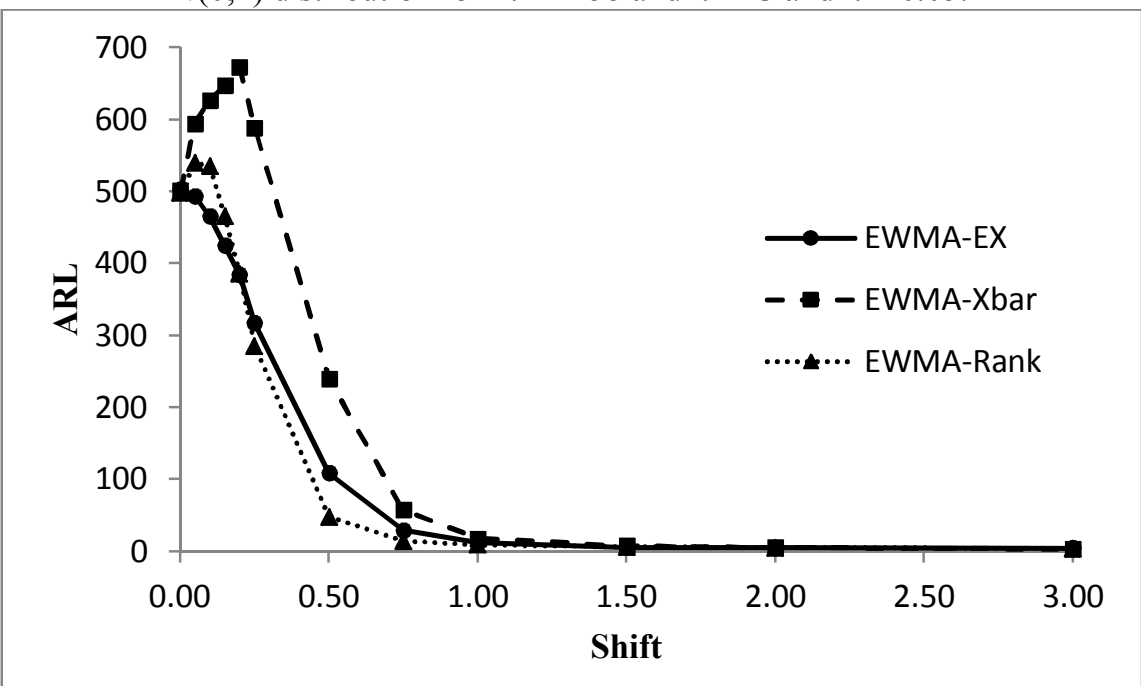

Figure 4a. $A R L$ performance comparison of the competing charts under the $\operatorname{EXP}(1)$ distribution for $m=100$ and $n=5$ and $\lambda=0.05$.

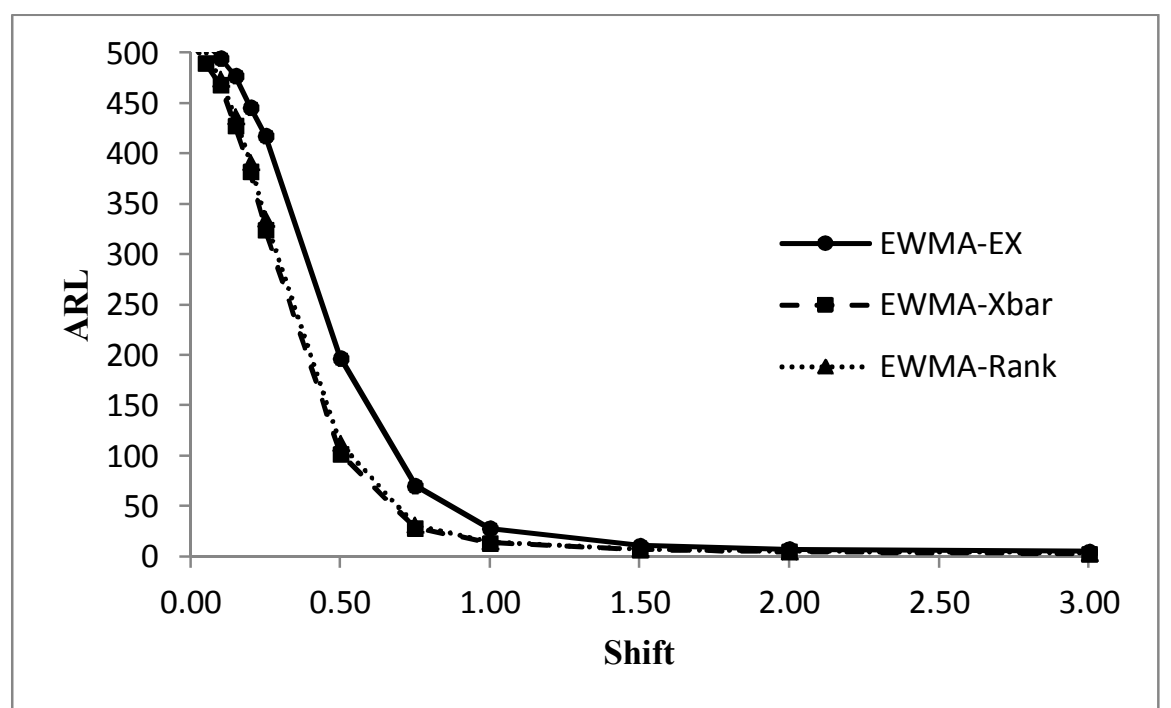

Figure 3b. $A R L$ performance comparison of the competing charts under the $N(0,1)$ distribution for $m=100$ and $n=5$ and $\lambda=0.10$.

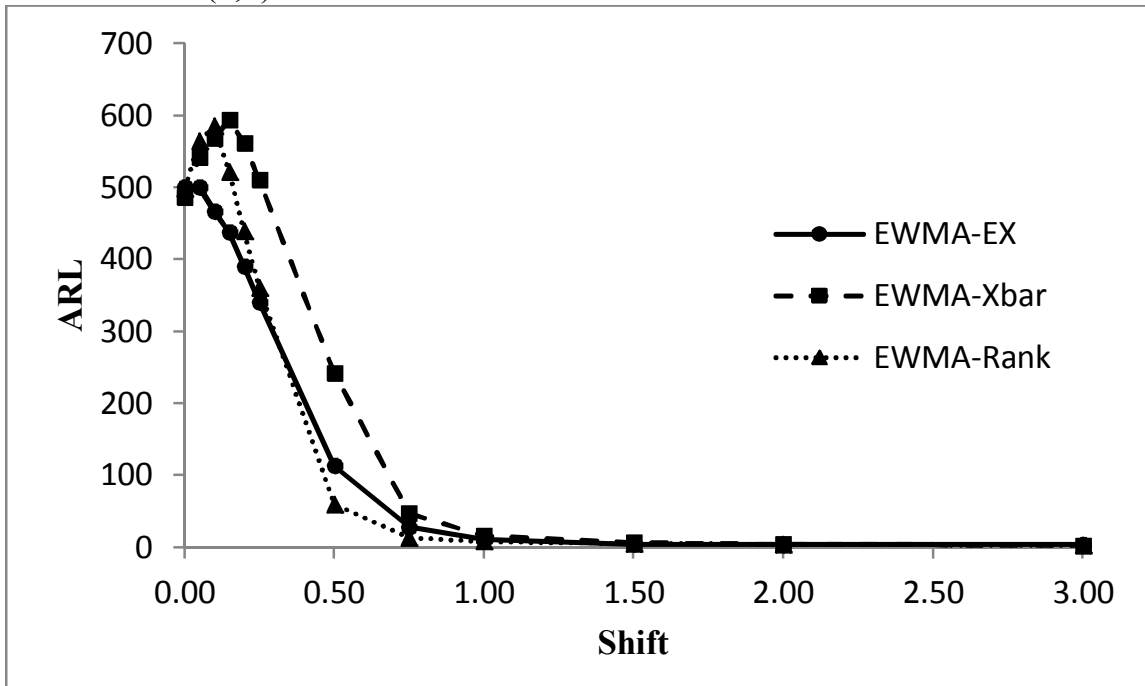

Figure 4b. $A R L$ performance comparison of the competing charts under the $E X P(1)$ distribution for $m=100$ and $n=5$ and $\lambda=0.10$. 


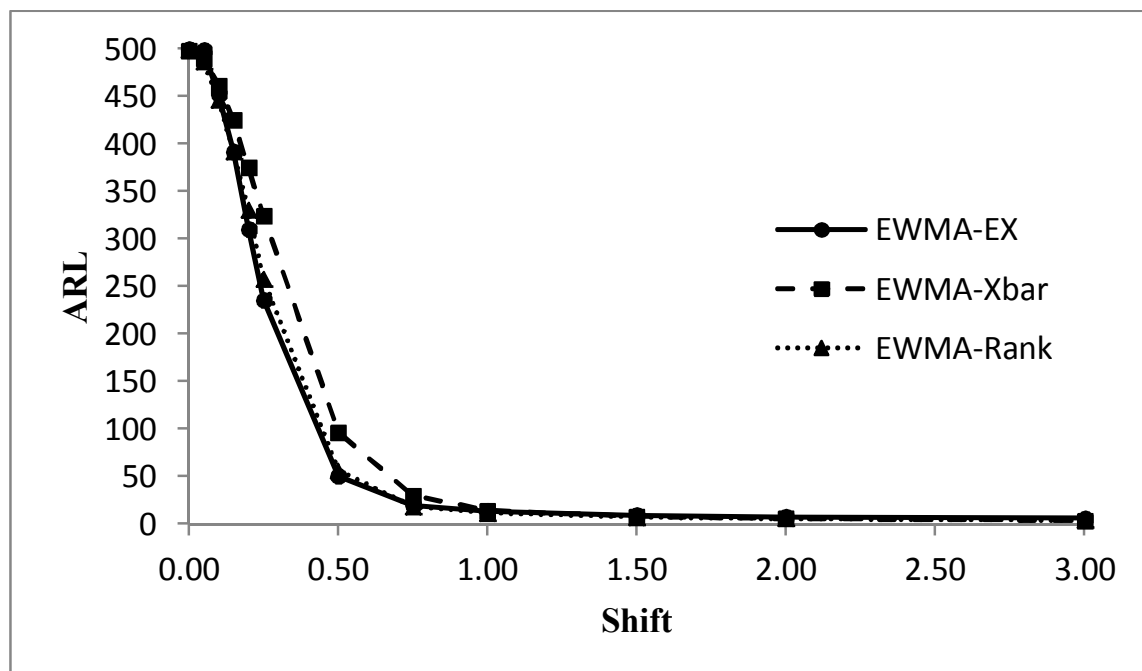

Figure 5a. $A R L$ performance comparison of the competing charts under the $D E(0,1)$ distribution for $m=100$ and $n=5$ and $\lambda=0.05$.

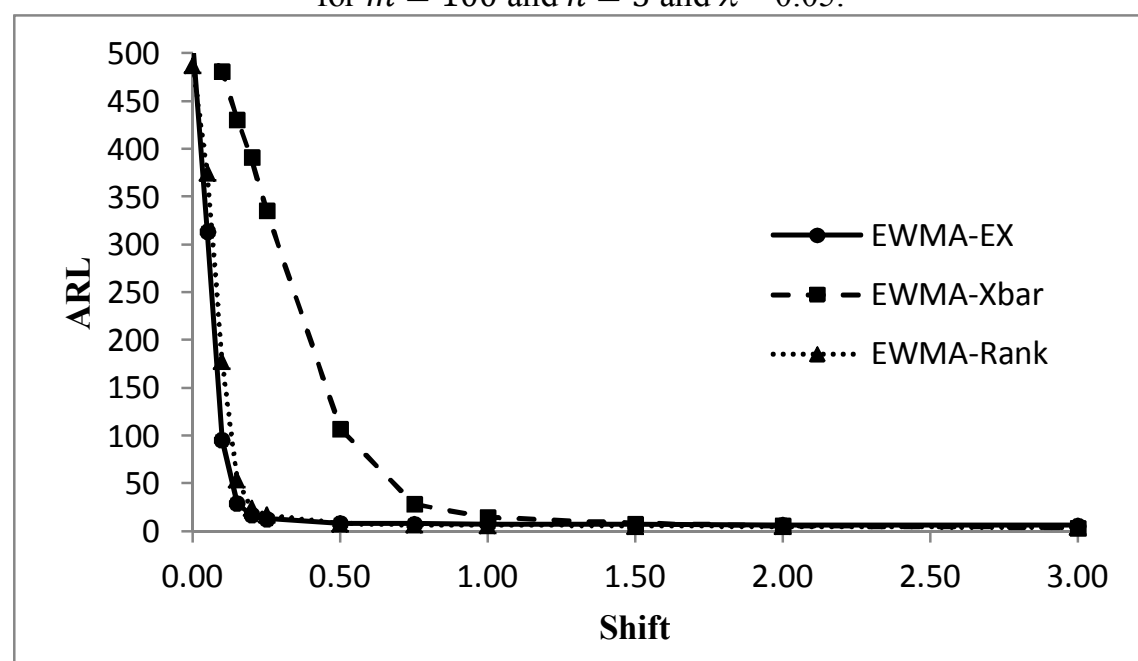

Figure 6a. $A R L$ performance comparison of the competing charts under the Symmetric Mixture Normal distribution for $m=100$ and $n=5$ and $\lambda=0.05$.

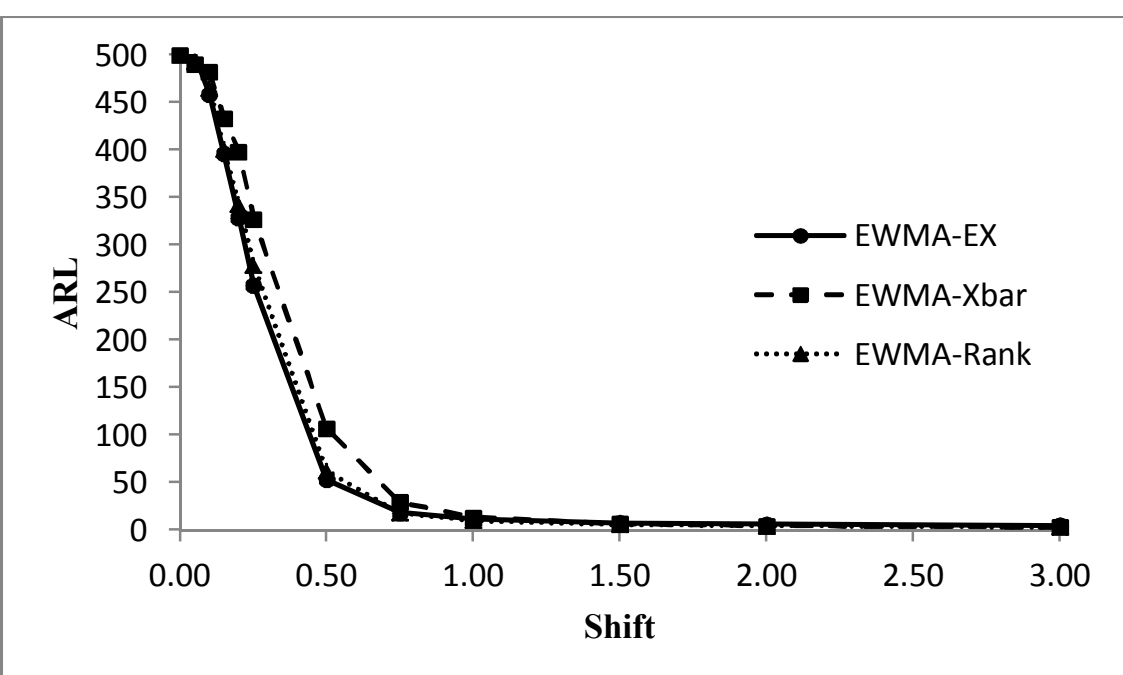

Figure 5b. $A R L$ performance comparison of the competing charts under the $D E(0,1)$ distribution for $m=100$ and $n=5$ and $\lambda=0.10$

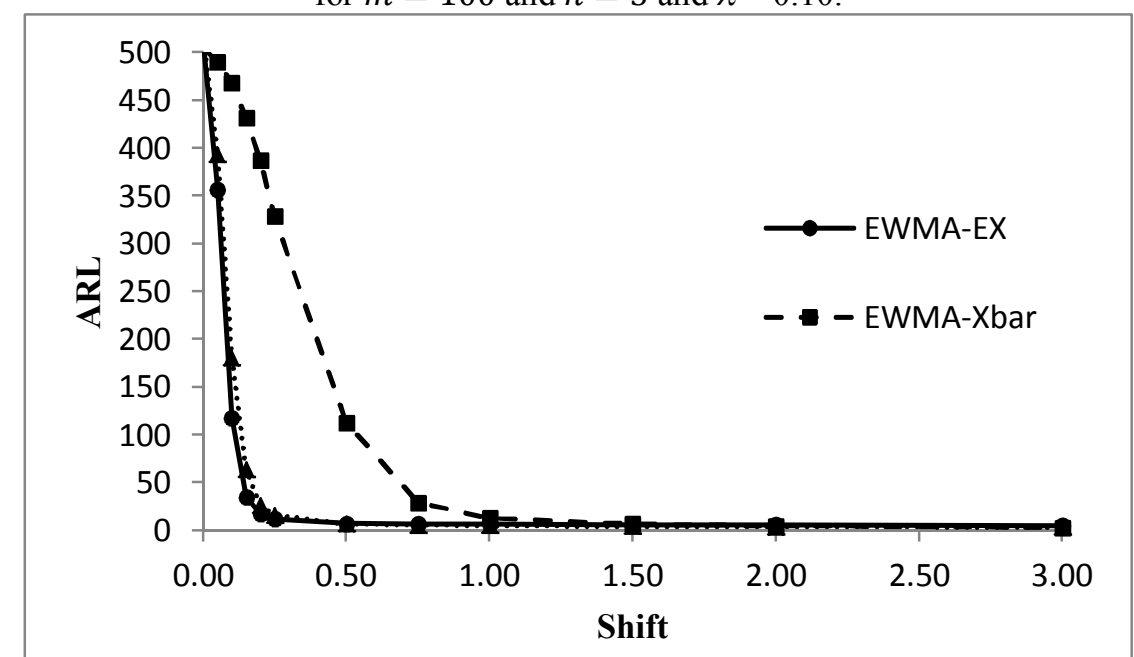

Figure 6b. $A R L$ performance comparison of the competing charts under the Symmetric Mixture Normal distribution for $m=100$ and $n=5$ and $\lambda=0.10$. 


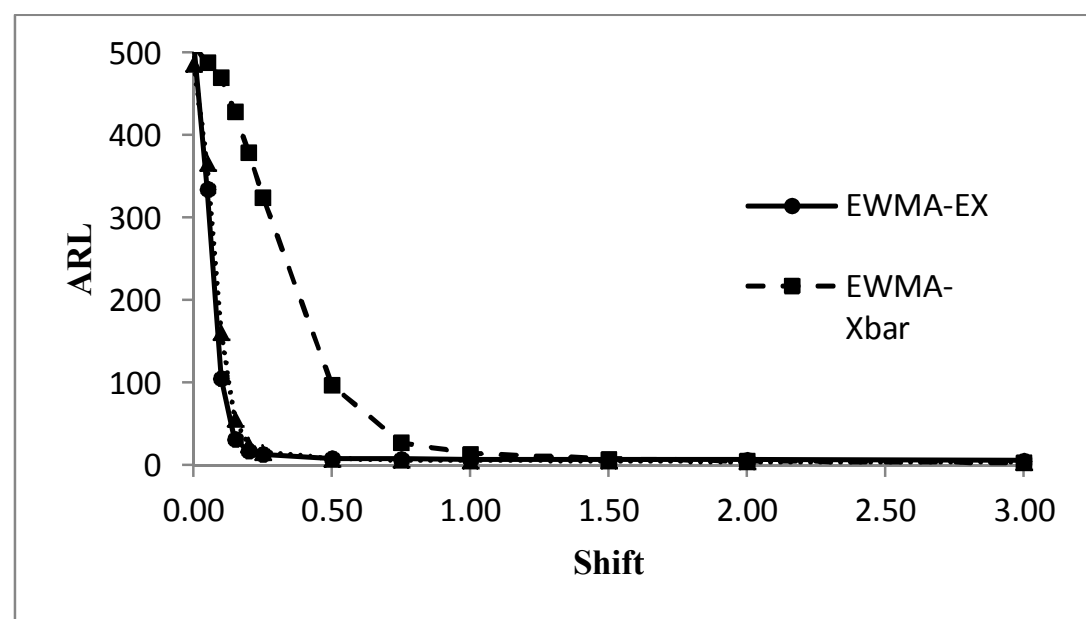

Figure 7a. $A R L$ performance comparison of the competing charts under the Asymmetric Mixture Normal distribution $\left[0.6 N\left(\mu_{1}=0.25, \sigma_{1}=0.25\right)+0.4 N\left(\mu_{2}=0, \sigma_{2}=4\right)\right]$ for $m=100$ and $n=5$ and $\lambda=0.05$.

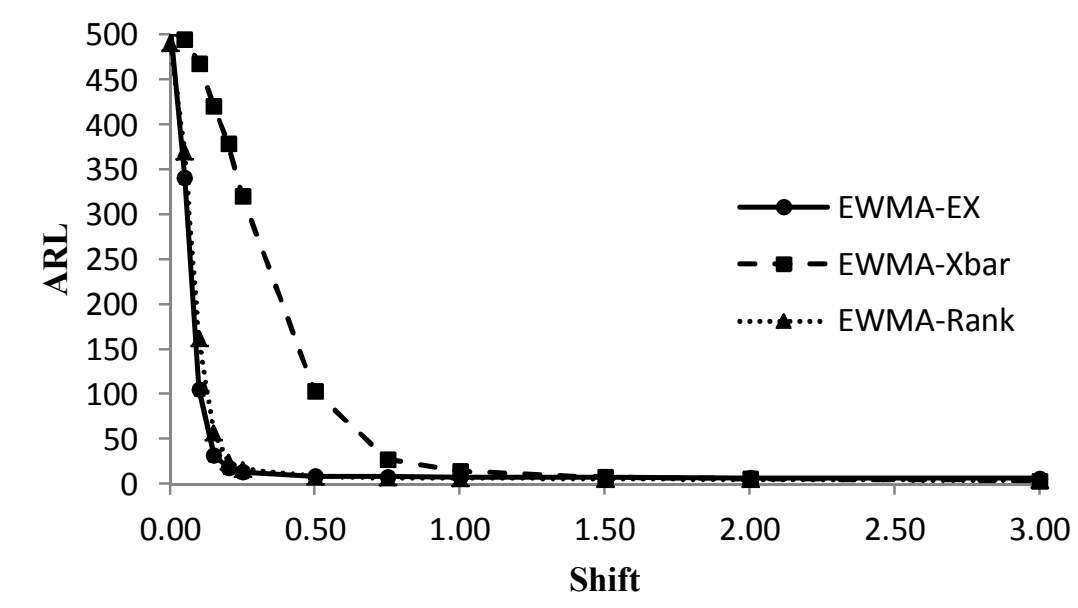

Figure 8a. $A R L$ performance comparison of the competing charts under the Asymmetric Mixture Normal distribution $\left[0.6 N\left(\mu_{1}=-0.25, \sigma_{1}=0.25\right)+0.4 N\left(\mu_{2}=0, \sigma_{2}=4\right)\right]$ for $m=100$ and $n=5$ and $\lambda=0.05$.

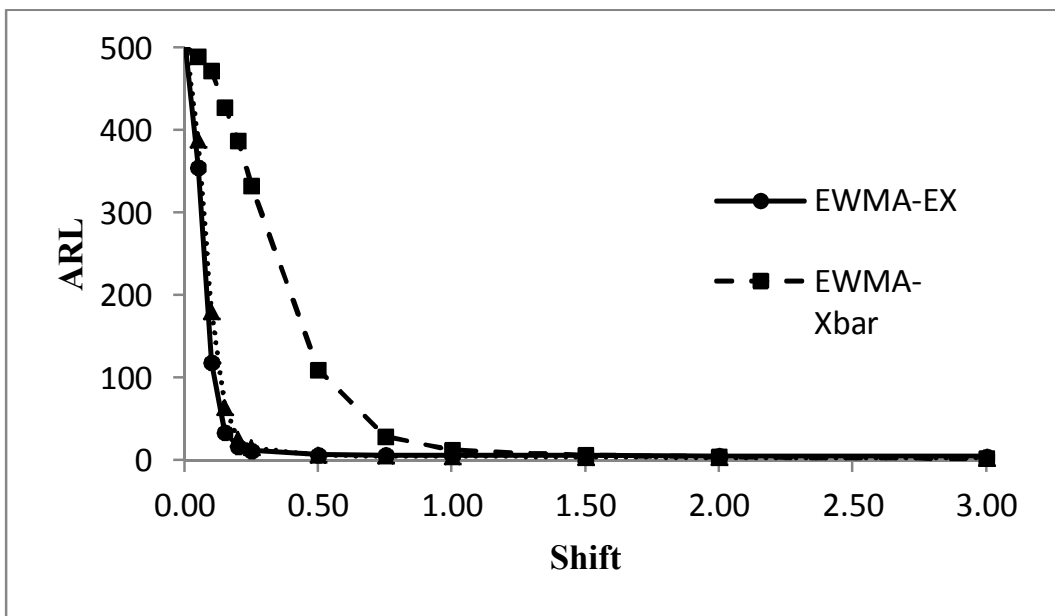

Figure 7b. $A R L$ performance comparison of the competing charts under the Asymmetric Mixture Normal distribution $\left[0.6 N\left(\mu_{1}=0.25, \sigma_{1}=0.25\right)+0.4 N\left(\mu_{2}=0, \sigma_{2}=4\right)\right]$ for $m=100$ and

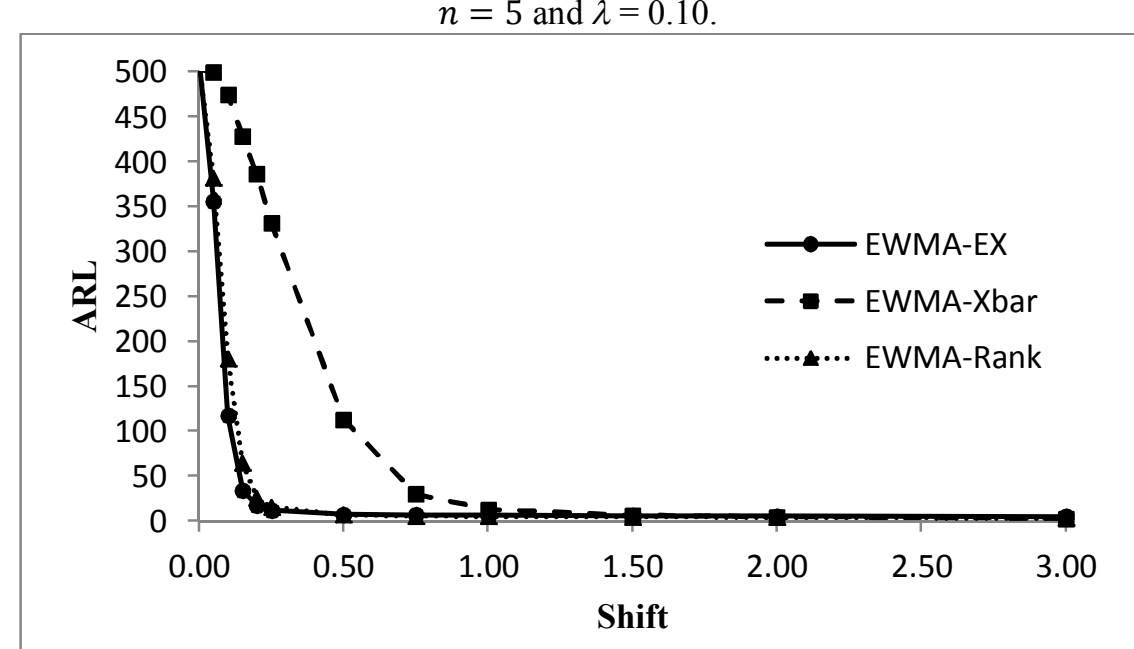

Figure 8b. $A R L$ performance comparison of the competing charts under the Asymmetric Mixture Normal distribution $\left[0.6 N\left(\mu_{1}=-0.25, \sigma_{1}=0.25\right)+0.4 N\left(\mu_{2}=0, \sigma_{2}=4\right)\right]$ for $m=100$ and $n=5$ and $\lambda=0.10$ 


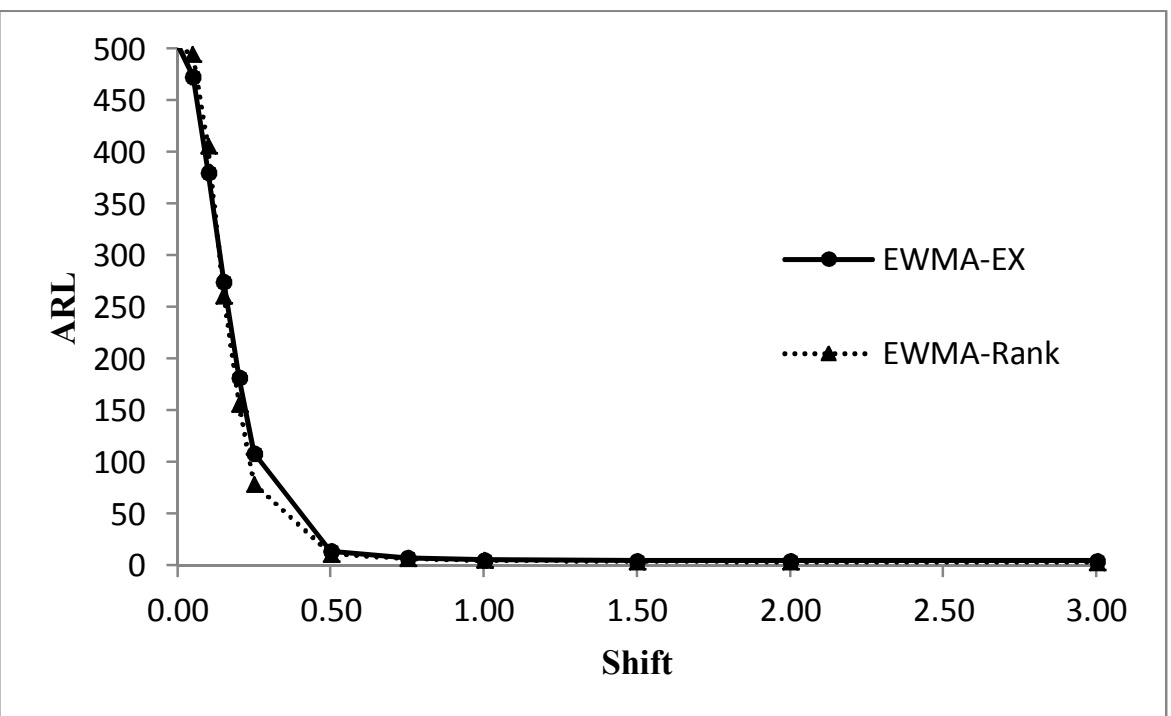

Figure 9a. $A R L$ performance comparison of the competing charts under the Log-Logistic distribution for $m=100$ and $n=5$ and $\lambda=0.05$.

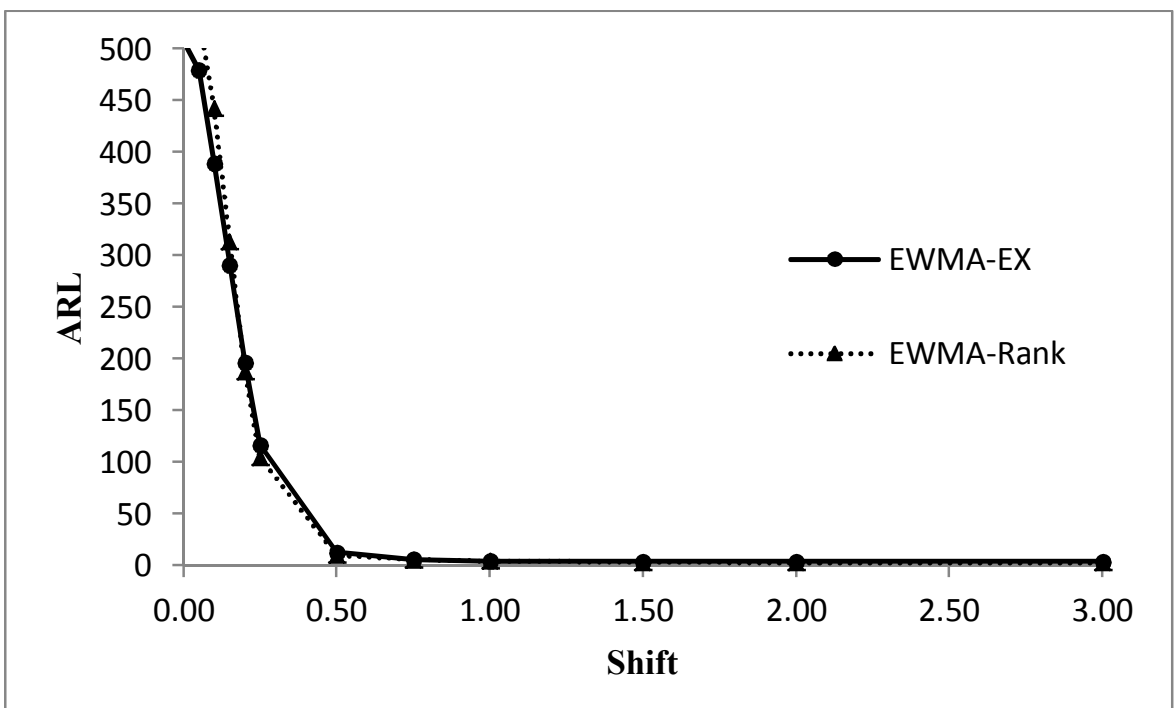

Figure 9b. $A R L$ performance comparison of the competing charts under the Log-Logistic distribution for $m=100$ and $n=5$ and $\lambda=0.10$. 


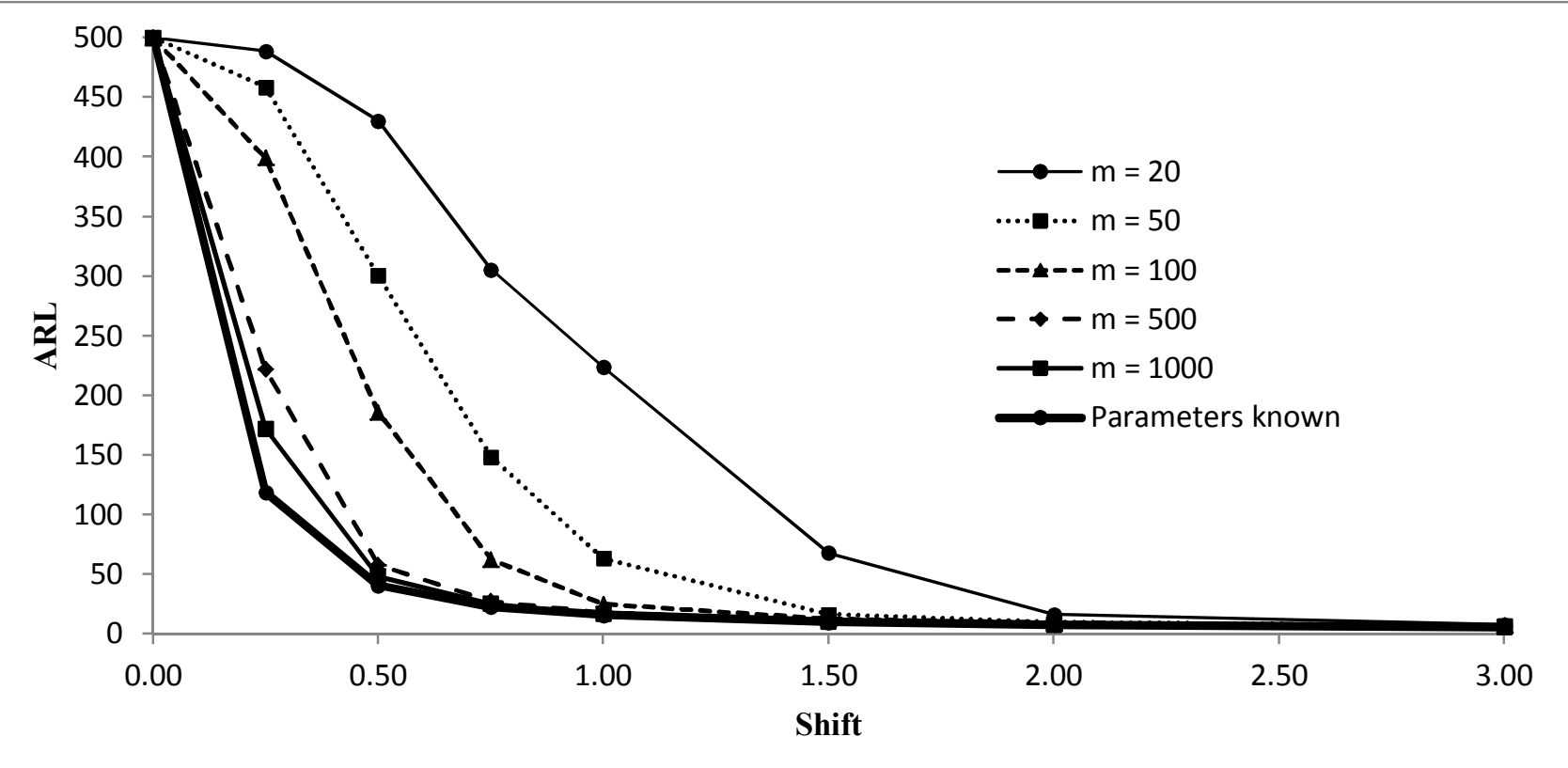

Figure 10. $A R L$ comparison for different reference sample sizes under the $N(0,1)$ distribution forn $=5$ and $\lambda=0.05$. 